CDD: 185

\title{
TERMOS SINGULARES, TRANSCATEGORIAIS E SUMMA GENERA NA LÓGICA DE ARISTÓTELES
}

\author{
WELLINGTON DAMASCENO DE ALMEIDA
}

Instituto de Filosofia e Ciências Humanas

Departamento de Filosofia

Universidade Estadual de Campinas

Cidade Universitária Zeferino Vaz.

13083-896 CAMPINAS, SP

BRASIL

wellington.damasceno@gmail.com

Received: 27.03.2012; Revised: 15.09.2012; Accepted: 22.11.2012

\begin{abstract}
Resumo: Quais termos são suscetíveis de operações silogísticas? Para importantes intérpretes da lógica aristotélica - especialmente Ross, Patzig e Lukasiewicz - a resposta tende a introduzir um único e homogêneo grupo de termos, aqueles de generalidade intermediária ( $(\grave{\alpha} \mu \varepsilon \tau \alpha \xi \dot{u})$. Fundamentada basicamente na classificação tripartite de entes que aparece no capítulo 27 de Primeiros Analíticos I, essa opinião atribui à silogística a exclusão de (i) termos singulares (como "Sócrates" e "este homem"), (ii) transcategoriais (como "ente" e "um"), bem como dos chamados (iii) summa genera ("substância", "qualidade", "quantidade", etc.). Em nossa opinião, esses resultados não derivam dos textos de Aristóteles, mas de leituras, traduções e interpretações impróprias das passagens centrais da discussão. Neste artigo, faremos um novo exame desses textos, a fim de mostrar que Aristóteles jamais afastou de sua lógica os tipos de termos que os intérpretes não hesitam em excluir da silogística. Assim, esperamos reintroduzir termos singulares, transcategoriais e summa genera, no domínio da silogística aristotélica.
\end{abstract}

Palavras chave: Aristóteles. Silogística. Termos Singulares. Transcategoriais. Summa Genera.

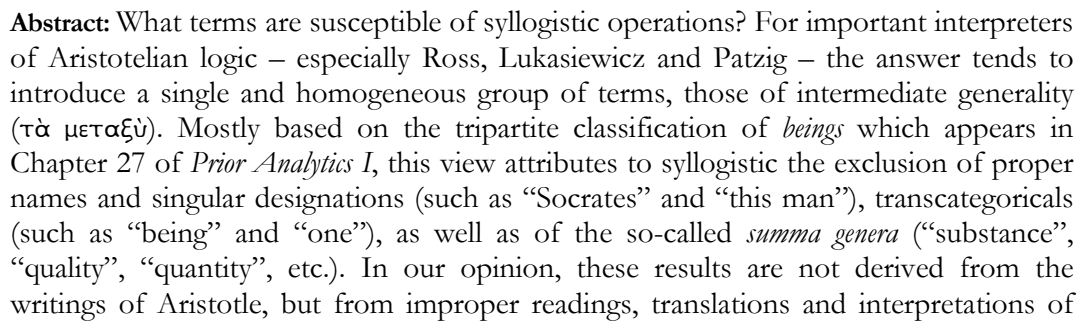
Manuscrito - Rev. Int. Fil., Campinas, v. 36, n. 1, p. 5-48, jan.-jun. 2013. 
the central passages for the discussion. In this paper, we will make a further examination of these texts in order to show that Aristotle has never departed from his logic the types of terms that interpreters do not hesitate to exclude from syllogistic. Thereby, we hope to bring back singular terms, transcategoricals and summa genera to the operation domain of the Aristotelian syllogistic.

Keywords: Aristotle. Syllogistic. Singular Terms. Transcategoricals. Summa Genera.

\section{OPINIÕES TRADICIONAIS}

Já faz algum tempo que a silogística aristotélica vem sendo pensada como um sistema lógico marcado pela exclusão de certos termos. De acordo com importantes estudiosos, ela não reserva lugar para nomes próprios e designações singulares, como "Cálias" e "este homem", tampouco para termos transcategoriais, como "ente" (to on) e "um" (to hen). Há quem diga que nem mesmo os chamados gêneros supremos (summa genera) - "substância", "qualidade", "quantidade", e assim por diante - estão aptos a figurar em silogismos rigorosamente aristotélicos.

Essa linha de opiniões parece ter sido inaugurada por W. D. Ross, em 1949, com a publicação de sua famosa edição comentada do texto grego de Primeiros e Segundos Analíticos. Em seu comentário ao primeiro capítulo do Livro I dos Primeiros Analíticos, Ross não hesita em dizer que Aristóteles teria ignorado completamente os termos singulares. Além disso, ainda observa que o argumento considerado como modelo paradigmático de um silogismo tipicamente aristotélico - argumento amplamente difundido pelos manuais de lógica, formulado em primeira figura, com ambas as premissas afirmativas, no qual um termo singular aparece como sujeito da premissa menor e da conclusão ${ }^{1}$ - passa longe dos silogismos encontrados nos Primeiros Analíticos. De acordo com Ross, todos os silogismos apresentados nos Primeiros Analiticos versam sobre universais (termos conceituais) e, mais do que isso, todos possuem

\footnotetext{
1 O silogismo é o seguinte: “todo homem é mortal, Sócrates é homem; logo, Sócrates é mortal".
}

Manuscrito - Rev. Int. Fil., Campinas, v. 36, n. 1, p. 5-48, jan.-jun. 2013. 
um termo-espécie na posição de extremo menor. Por fim, sem fazer cerimônia, Ross assume que Aristóteles teria restringido a silogística a argumentos que articulam exclusivamente termos universais (conceituais) e aponta que as razões para fazê-lo repousariam ("probably") no argumento exposto no capítulo 27 do Livro I de Primeiros Analíticos (em especial no trecho 43a 42-43). Mais tarde, esse capítulo se consolidaria como manifesta evidência de que a silogística de Aristóteles envolve uma severa restrição de termos ${ }^{2}$.

No capítulo 27 do Livro I de Primeiros Analíticos, Aristóteles propõe, entre outras coisas, uma classificação de entes - compreendidos como fatores de atribuição ou simplesmente como termos - fundada no comportamento atributivo e no grau de generalidade dos itens classificados. Como resultado, Aristóteles alcança três tipos de termos: (1) aqueles desprovidos de generalidade, que não podem ser atribuídos como legítimos predicados de outros termos, mas aos quais outros termos podem ser atribuídos - é o caso dos nomes próprios “Cleon" e "Cálias"; (2) aqueles de mais alta generalidade, que podem ser atribuídos a outros termos e para os quais não existe termo anterior

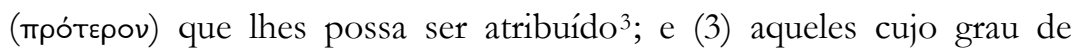

\footnotetext{
${ }^{2}$ Ross (1949, p. 289), Lukasiewicz (1951, p. 4-5), G. Patzig (1959, p. 5).

3 Aristóteles não oferece nenhum exemplo para termos do segundo tipo. $\mathrm{Na}$ opinião de Ross (1949, p. 384), "these are the highest universals, the categories". Já para Lukasiewicz (1951, p. 5), "it is clear that Aristotle means what is most universal, like being, to on". Embora seja difícil decidir por uma dessas opiniões - sobretudo porque não sabemos o que significa прótepov em 43a 30 - a alternativa de Lukasiewicz ainda nos parece menos sujeita a objeções. De fato, se Ross tem razão em compreender os termos do segundo tipo como summa genera ("substância", "qualidade", "quantidade", etc.), a impossibilidade de lhes atribuir predicados anteriores (про́тєроv), apontada nas linhas 43a 29-30, deverá ser muito bem especificada, de modo a evitar uma objeção bem natural, a de que nem mesmo summa genera podem satisfazer a exigência das referidas linhas, já que, a princípio, nada impede que termos transcategoriais como "ente" e "um" sejam concebidos como predicados anteriores dos chamados summa genera. Certamente, a indefinição do sentido de
} 
generalidade é intermediário, que podem ser atribuídos a outros termos e aos quais outros termos podem ser atribuídos - é o caso do termo "homem" 4 .

Depois de expor os três tipos de termos alcançados pela classificação referida acima, Aristóteles conclui o trecho 43a 25-43 com a frase que deu ignição às interpretações que atribuem ao sistema lógico aristotélico a já mencionada restrição de termos. Eis a frase:

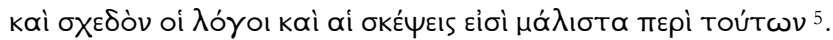

Grosso modo, os argumentos e as investigações são sobretudo acerca dessas coisas. (43a 42-43).

mpótepov, na linha 30, ainda deixa espaço para associar à noção de predicado anterior um significado que seja incompatível com os termos transcategoriais mencionados acima. Essa alternativa poderia encontrar alguma inspiração em Metafísica XII 4, em que Aristóteles nos diz que "à parte das substâncias e das demais categorias, não há nada comum" (1070b 1-2). A impossibilidade de algo comum à parte das categorias poderia ser interpretada como uma impossibilidade de conceitos transcategoriais, o que favoreceria a proposta de Ross. Tal leitura, no entanto, conflita com passagens nas quais Aristóteles trabalha com predicados de todas as coisas - o que se confirma pelo uso da

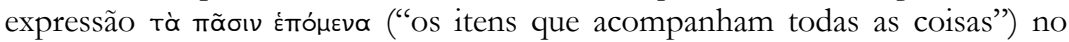

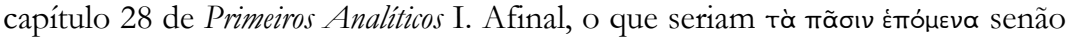
conceitos transcategoriais? E por que tais predicados não seriam candidatos mais promissores que os summa genera para figurar na lista de termos do segundo tipo? Diante desse quadro, a proposta de Lukasiewicz nos parece preferível, na medida em que evita as dificuldades aludidas acima. Além disso, no que diz respeito aos propósitos deste artigo, faz pouca ou nenhuma diferença se tais termos são (i) summa genera ou (ii) Tà mãoıv Ėாóneva (embora tenhamos maior estima pela segunda opção), uma vez que a nossa posição antecede à decisão entre essas duas alternativas e procura responder uma questão mais elementar, a saber: Aristóteles de fato excluiu da silogística os termos de alta generalidade (quer sejam summa genera, quer sejam tà mãoı غ̇пónєva)? Para essa questão mais básica, defenderemos uma resposta negativa. 4 An. Pr. I 27, 43a 37-43.

${ }^{5}$ Adotamos o texto grego de W. D. Ross em todas as citações.

Manuscrito - Rev. Int. Fil., Campinas, v. 36, n. 1, p. 5-48, jan.-jun. 2013. 
O pronome toútwv retoma os termos qualificados sob o terceiro tipo, anunciados nas linhas 40-42. Conforme já vimos, esses termos nem são de natureza singular, como nomes próprios e designações singulares, nem são os de mais alta generalidade, como summa genera e/ou transcategoriais. Na verdade, quanto ao grau de generalidade, tais fatores se posicionam entre os demais tipos de termos e, por isso

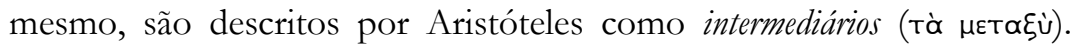
Para ilustrar a natureza desse tipo de termo, Aristóteles apresenta "homem", que se predica de "Cálias" e do qual "animal" se predica, irrestritamente ${ }^{6}$.

Ao comentar o trecho 43a 37-43, que encerra com a frase que inspirou a exclusão dos mencionados termos, Ross acaba sendo mais cauteloso do que fora no comentário ao primeiro capítulo do Livro I de Primeiros Analíticos. Ele entende que, no referido trecho do capítulo 27, Aristóteles esteja, de fato, comprometido com uma restrição associada aos termos, mas assume que essa restrição diz respeito à suscetibilidade de desempenhar irrestritamente as funções de maior (тò $\mu \varepsilon \tilde{\zeta}$ ov), menor (Tò

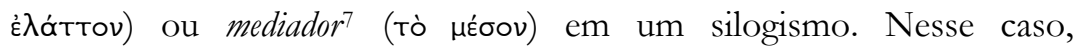
Aristóteles não estaria restringindo o domínio de fatores sobre os quais a silogística pode operar, mas o domínio de fatores que podem exercer irrestritamente cada uma das três funções que um termo pode desempenhar em um silogismo.

\footnotetext{
${ }^{6}$ Ibidem, 43a 31-32.

7 A proposta de traduzir meson como "mediador" (Angioni, 2007, nota 6) - e não "termo médio", como de costume, ou "termo intermediário" - nos parece bastante acertada. Em nossa opinião, ela capta com precisão a função mais básica do meson, qual seja, a de articular ou correlacionar os termos da conclusão. Por isso, decidimos adotá-la. Aos poucos, essa alternativa de tradução vem ganhando espaço. Em 2010, durante o $I^{0}$ Ciclo de Seminários 'O Organon de Aristóteles', realizado na Universidade de Campinas, Ricardo Santos (Universidade de Évora - Portugal) se mostrou de pleno acordo com a opção por "mediador", embora não a tenha adotado na tradução que vem preparando.
}

Manuscrito - Rev. Int. Fil., Campinas, v. 36, n. 1, p. 5-48, jan.-jun. 2013. 
$\mathrm{Na}$ primeira figura, por exemplo, apenas os termos de generalidade intermediária (т⿳亠㐅 $\mu \varepsilon т \propto \xi \grave{u}$ ) são capazes de desempenhar irrestritamente a função de mediador. De fato, os demais termos só podem atuar de modo irrestrito nos silogismos de primeira figura quando ocupam as posições ou de sujeito ou de predicado, ao passo que o mediador é sujeito $e$ predicado, sujeito na premissa maior e predicado na menor. Ross também observa que os gêneros supremos ("the highest terms") podem desempenhar irrestritamente a função de extremo maior, bem como os termos desprovidos de generalidade ("the lowest terms"), a função de extremo menor. Ademais, continua Ross, os gêneros supremos ainda podem atuar de modo irrestrito na função de mediador, na segunda figura, assim como os termos singulares, na terceira figura.

Até esse ponto, o comentário de Ross ao capítulo 27 não introduz nenhuma severa restrição de termos, sobretudo porque o trecho $43 \mathrm{a}$ 37-43, assim como o início do capítulo, não lhe permitem ir muito longe. Tudo o que esses textos nos impõem é que, nas demonstrações, certos termos não podem ocupar irrestritamente a posição de sujeito, ao passo que outros não podem ocupar irrestritamente a posição de predicado. Assim, Aristóteles abre espaço para a possibilidade de que os termos singulares tenham o seu lugar ao sol na silogística, desde que sejam alocados em posições e funções que possam desempenhar sem as restrições mencionadas ao longo do capítulo 27. Ross parece ter se dado conta disso e, ao que tudo indica, não gostou do que viu, pois encerra as suas considerações sobre o trecho 43a 37-43 tentando recuperar aquela restrição de termos que já havia sido apresentada no comentário ao capítulo 1 de Primeiros Analíticos I, alegando que Aristóteles nunca usa nomes próprios e designações singulares em seus exemplos de silogismos, mas apenas termos de generalidade

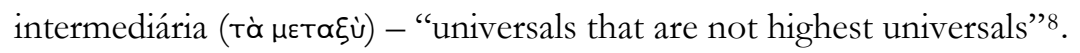

\footnotetext{
${ }^{8}$ Ross (1949, p. 384).

Manuscrito - Rev. Int. Fil., Campinas, v. 36, n. 1, p. 5-48, jan.-jun. 2013.
} 
Podemos dizer que Ross nos deixou o seguinte legado: por um lado, é responsável pela tradicional opinião de que Aristóteles nunca se vale de termos singulares ou gêneros supremos em seus silogismos, mas sempre trabalha com termos de generalidade intermediária; por outro lado, transformou o capítulo 27 de Primeiros Analíticos I em peça central para a delimitação da lista de termos silogísticos.

Em 1951, Jan Lukasiewicz publicou o seu famoso livro, intitulado Aristotle's Syllogistic - From The Standpoint of Modern Formal Logic, e se mostrou bastante influenciado pelo legado de Ross. Já no primeiro capítulo desse livro, Lukasiewicz se recusa a considerar como rigorosamente aristotélico aquele argumento concebido pela tradição como exemplo paradigmático de silogismo - "todo homem é mortal, Sócrates é homem; logo, Sócrates é mortal” - levando a cabo algo que Ross já havia sugerido em seu comentário ao capítulo 1 do Livro I de Primeiros Analíticos, a saber, que tal argumento não pertence à lógica de Aristóteles ${ }^{9}$. Lukasiewicz qualifica esse silogismo por meio do adjetivo "peripatético", pelo fato de Sexto Empírico descrevê-lo como usual entre os Peripatéticos. Quanto à rejeição desse silogismo, provisoriamente Lukasiewicz alega apenas que Aristóteles não introduz termos e proposições singulares em seu sistema lógico ${ }^{10}$. A completa ausência de referência a proposições singulares no capítulo 1 do Livro I dos Primeiros Analíticos - capítulo em que as formas proposicionais silogísticas são introduzidas e no qual seria natural esperar por proposições singulares - é mencionada por Lukasiewicz como sinal de que Aristóteles não teria considerado termos singulares em sua lógica ${ }^{11}$. No entanto, o argumento determinante para corroborar essa tese é

\footnotetext{
${ }_{9}^{9}$ Ross (1949, p. 289) e Lukasiewicz (1951, chapter 1, §1, p. 1).

10 Lukasiewicz menciona três publicações que tratavam o silogismo peripatético como modelo paradigmático de silogismo aristotélico: Greek Foundations of Tradicional Logic (1942), de Ernest Kapp; A History of Philosophy, vol. i: Greece and Rome (1946), de S. J. Frederick Copleston; e History of Western Philosophy (1946), de Bertrand Russell.

11 Idem, chapter 1, $₫ 2$, p. 4.
}

Manuscrito - Rev. Int. Fil., Campinas, v. 36, n. 1, p. 5-48, jan.-jun. 2013. 
elaborado a partir do capítulo 27 do Livro I de Primeiros Analíticos, capítulo já evocado por Ross como evidência manifesta da restrição de termos.

Conforme já pudemos ver, é no capítulo 27 que Aristóteles apresenta sua famosa tripartição de entes, assumidos como termos de proposições silogísticas: nas linhas 43 a $25-36$, os três tipos de termos são introduzidos; nas linhas 37-42, os efeitos que essa tripartição tem sobre as demonstrações são rapidamente considerados; em seguida, nas linhas 42-43, entra em cena a frase que inspirou a restrição de termos já nos comentários de Ross e ainda mais na proposta de Lukasiewicz. Interpretando Aristóteles, Lukasiewicz conclui que a silogística opera exclusivamente com termos do último tipo, isto é, com termos de generalidade intermediária (тò $\mu \varepsilon \tau \alpha \xi \grave{u}$ ), excluindo da lógica aristotélica tanto os termos singulares quanto os de alta generalidade - os últimos, assumidos como "ente" e "um"12. Julgando ter encontrado a "verdadeira razão" que teria levado Aristóteles a se comprometer com tal restrição de termos, Lukasiewicz alega que todo silogismo deve conter um termo capaz de desempenhar irrestritamente tanto a função de sujeito quanto a função de predicado - na primeira figura, é o que ocorre com o mediador, na segunda, com o maior, na terceira, com o menor - e essas funções só podem ser desempenhadas irrestritamente por termos de generalidade intermediária ${ }^{13}$. Ao que tudo indica,

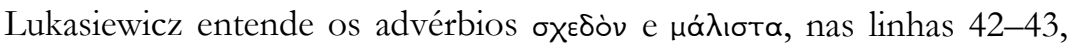
como marcas que qualificam o restante da frase como uma regra absoluta e universal, afastando a possibilidade de que Aristóteles esteja apenas se pronunciando em linhas gerais, sem qualquer pretensão de

12 Idem, \3, p. 5. Convém lembrar que Lukasiewicz e Ross não têm a mesma opinião sobre o que seriam os termos de alta generalidade, aos quais Aristóteles alude em 43a 29-30 e 37-39: para Lukasiewicz, os termos de alta generalidade são precisamente os transcategoriais "ente" e "um", ao passo que Ross prefere concebê-los como summa genera (cf. nota 3 ).

13 Ibidem, p. 7.

Manuscrito - Rev. Int. Fil., Campinas, v. 36, n. 1, p. 5-48, jan.-jun. 2013. 
estabelecer uma norma rígida, válida para todo e qualquer silogismo, mas apenas uma descrição que pudesse dar conta da maior parte dos argumentos silogísticos. Essa atitude o levou a fazer duras críticas à lógica aristotélica.

De acordo com Lukasiewicz, é questão pacífica a opinião de que os termos singulares são tão importantes na atividade científica quanto o são os termos universais e, portanto, é falso que os argumentos e as investigações "as a rule" lidam com termos de universalidade

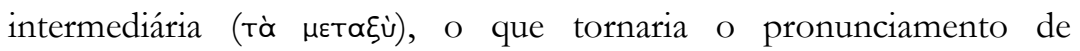
Aristóteles, nas linhas 42-43, digno de reprovação. Com esse teor, Lukasiewicz atribui a Aristóteles a rejeição dos termos singulares e descreve a ausência desses fatores como "o maior defeito" do sistema lógico aristotélico ${ }^{14}$.

Assim, inspirado pelo legado de Ross, Lukasiewicz consolida a opinião de que a silogística aristotélica envolve uma severa restrição de termos, constituindo um sistema lógico que atua exclusivamente sobre termos de generalidade intermediária (тò $\mu \varepsilon \tau \alpha \xi \grave{u})$. Sob a descoberta da "verdadeira razão" que teria levado Aristóteles a se comprometer com essa restrição de termos, Lukasiewicz estabelece a tese de que a silogística prescinde de termos singulares bem como de termos de alta generalidade ("ente" e "um”).

Essa proposta foi muito bem recebida por alguns estudiosos da lógica aristotélica. Em 1959, Günther Patzig publicou um novo estudo sobre o Livro I dos Primeiros Analíticos e fez questão de dedicá-lo a Lukasiewicz, de quem é seguidor. Em obra intitulada Aristotle's Theory of the Syllogism - a logico-philological study of book. A of the Prior Analytics, Patzig corrige vários equívocos herdados de Ross e de Lukasiewicz. Para ilustrar, considere-se a alegação - feita tanto por Ross quanto por Lukasiewicz - de Aristóteles nunca se valer de termos singulares nos Primeiros Analíticos. Essa alegação é desmentida por Patzig, que aponta

${ }^{14}$ Ibidem, p. 6.

Manuscrito - Rev. Int. Fil., Campinas, v. 36, n. 1, p. 5-48, jan.-jun. 2013. 
as seguintes ocorrências de nomes próprios: no capítulo 33 do Livro I, "Aristomenes" e "Micalos", no capítulo 27 do Livro II, "Pitacos". Mesmo diante dessas ocorrências, Patzig recusou a possibilidade de a silogística reservar lugar para termos singulares, justificando tal posição ao apontar que "Aristomenes" e "Micalos" aparecem em premissas das quais nada se segue, ao passo que "Pitacos" ocorre em um silogismo que não é outra coisa senão inválido. Em presença desse quadro e a exemplo de Lukasiewicz, Patzig considera que deve prevalecer o fato indubitável de Aristóteles não ter feito menção a proposições singulares no capítulo 1 de Primeiros Analíticos I, o que fatalmente sugere a exclusão dos termos singulares ${ }^{15}$. Assim, Patzig é levado a endossar diversos resultados alcançados por seus antecessores, reiterando a restrição de fatores silogísticos a termos de generalidade intermediária (тò $\mu \varepsilon т \alpha \xi \dot{u})$ e, por conseguinte, expulsando termos singulares, transcategoriais ("ente" e "um") e summa genera do sistema lógico aristotélico.

No entanto, sob a consideração de Patzig, essa restrição ganhou razões complementares. Patzig não apenas endossou os resultados sensivelmente sugeridos por Ross e consolidados por Lukasiewicz (resultados fundados no capítulo 27 do Livro I dos Primeiros Analíticos), mas também lhes conferiu novos contornos, oriundos de razões que julgou encontrar no capítulo 28, do qual o capítulo 27 seria discussão preparatória.

No capítulo 28, Aristóteles apresenta alguns procedimentos de prova para as formas proposicionais categóricas $(a, e, i$ e $o$ ). Em linhas gerais, esses procedimentos são caracterizados pela tarefa de identificar um termo comum (que será o mediador) em duas listas de termos. Essas listas são determinadas pela relação que os seus membros possuem com os extremos ( $($ ó ökpo), que encerram a conclusão pretendida.

${ }^{15}$ Patzig (1959, §3, p. 4-5).

Manuscrito - Rev. Int. Fil., Campinas, v. 36, n. 1, p. 5-48, jan.-jun. 2013. 
Ainda não precisamos entrar em detalhes a respeito desses procedimentos. Faremos isso na próxima seção, em momento mais oportuno. Por ora, basta saber que, a partir dos procedimentos recomendados por Aristóteles como estratégia de prova para cada uma das formas proposicionais categóricas $(a, e, i$ e $o$ ), Patzig propõe três axiomas demarcadores de termos que integram o domínio de operação da silogística ${ }^{16}$ :

(1) todo termo silogístico possui ao menos um termo subordinado próprio; ou seja, para todo termo silogístico $T$, existe um termo subordinado $X$ tal que $X a T$ é o caso, ao passo que $T a X$, não;

(2) todo termo silogístico possui ao menos um termo superordenado próprio; ou seja, para todo termo silogístico $T$, existe um termo superordenado $Y$ tal que TaY é o caso, ao passo que $Y a T$, não;

(3) todo termo silogístico possui um termo contrário; ou seja: para todo termo silogístico $T$, existe ao menos um termo contrário $Z$ tal que $Z e T^{17}$.

Ao formular os dois primeiros axiomas, Patzig se vale de algumas noções oriundas da teoria dos conjuntos, as noções de subordinação e superordenação próprias. Em teoria dos conjuntos, se $Q$ é um termo subordinado próprio de $R$ (e não apenas um termo subordinado), $Q$ e $R$ não podem ser coextensivos - em outras palavras, todo $Q$ é $R$, mas nem todo $R$ é $Q$; o mesmo ocorre com termos que freqüentam uma mesma relação de superordenação própria, dado que toda relação de subordinação própria pode ser reformulada como uma relação de superordenação própria e vice-versa. Patzig presume que essas relações traduzem pressupostos assumidos pelo próprio Aristóteles no capítulo

\footnotetext{
${ }_{16}^{16}$ Ibidem, p. 7.

${ }^{17}$ A notação $A \times B$, adotada na exposição dos axiomas, descreve uma relação categórica $x$ entre o termo-sujeito $A$ e o termo-predicado $B$. Assim, $A a B$ é a notação para a relação universal afirmativa ("todo A é B"), $A e B$, para a relação universal negativa ("nenhum $\mathrm{A}$ é B"), $A i B$, para a particular afirmativa ("algum $\mathrm{A}$ é B"), e, por fim, $A \circ B$, para a particular negativa ("algum $\mathrm{A}$ não é B"). Manteremos essa notação ao longo de todo o texto.
}

Manuscrito - Rev. Int. Fil., Campinas, v. 36, n. 1, p. 5-48, jan.-jun. 2013. 
28 de Primeiros Analiticos I. Mais adiante, veremos que essa conjetura é equivocada.

Por ora, é importante notar que essa distinção entre, de um lado, subordinação/superordenação própria e, de outro lado, mera subordinação/superordenação faz alguma diferença no que diz respeito à exclusão da chamada classe universal. Para excluí-la, Patzig assume que a classe universal pertence ao domínio de termos da silogística, a articula com os axiomas (1) e (3) e obtém um resultado contraditório: o terceiro axioma requer que todo termo silogístico possua ao menos um termo que lhe seja contrário - tratando-se da classe universal, esse termo contrário é a classe nula; por sua vez, o primeiro axioma requer que todo termo silogístico possua ao menos um termo subordinado próprio, exigência que a classe nula é incapaz de satisfazer - por definição, a classe nula não possui termos subordinados próprios. Assim, a impossibilidade da classe nula acarreta a impossibilidade da classe universal ${ }^{18}$.

Patzig ainda aponta o trecho 998b 22-27 do capítulo 3 de Metafísica Beta como evidência complementar de que Aristóteles teria rejeitado a classe universal, fazendo alusão a um texto que, embora trate de termos dessa natureza, tem com a silogística uma relação muito distante ${ }^{19}$.

Por sua vez, nomes próprios e designações singulares, como "Sócrates" e "este triângulo", não possuem termos subordinados próprios e, portanto, não satisfazem ao primeiro axioma. Por fim, gêneros supremos, como "substância", "qualidade", "quantidade", etc., não podem contar com termos superordenados próprios e, por conseguinte, ficam impossibilitados de satisfazer ao segundo axioma (impossibilidade que não nos parece ter sido bem estabelecida ${ }^{20}$ ).

\footnotetext{
18 Patzig (1959, §3, p. 4-5).

19 Ibidem.

20 A exemplo de Ross (cf. nota 3), Patzig ignora os transcategoriais "ente" e "um", que a princípio poderiam figurar como superordenados próprios dos gêneros supremos, de modo que o axioma (2) fosse então satisfeito pelos gêneros
}

Manuscrito - Rev. Int. Fil., Campinas, v. 36, n. 1, p. 5-48, jan.-jun. 2013. 
Assim, Patzig reitera as restrições introduzidas por Ross e consolidadas por Lukasiewicz, desenhando um quadro em que, uma vez mais, a silogística é pensada como um sistema lógico que opera exclusivamente sobre termos de generalidade intermediária (та̀ $\mu \varepsilon т \alpha \xi \grave{u})$, sem atuação sobre nomes próprios e designações singulares, gêneros supremos (summa genera) e termos transcategoriais ("ente" e "um"). $\mathrm{Na}$ próxima seção, mostraremos que as leituras propostas por tais intérpretes seguramente não encontram respaldo nos textos de Aristóteles.

\section{CRÍTICA ÀS OPINIÕES TRADICIONAIS}

\section{Uma Releitura de Primeiros Analíticos I 27, 43a 25-43}

Certamente, nem todo o legado de Ross, Lukasiewicz e Patzig deve ser abandonado. Parece razoavelmente acertada, por exemplo, a escolha do capítulo 27 do Livro I de Primeiros Analíticos como promissora resposta à questão de saber quais tipos de termos podem figurar em silogismos rigorosamente aristotélicos - muito embora nem todo tipo de silogismo reconhecido por Aristóteles esteja no escopo desse capítulo ${ }^{21}$. No primeiro capítulo do Livro I de Primeiros Analíticos, em que seria natural esperar alguma descrição mais detalhada a respeito dos termos, Aristóteles é muito sucinto, limitando-se a dizer o seguinte:

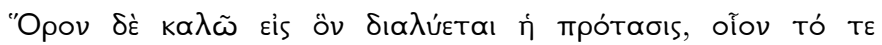

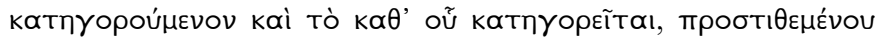

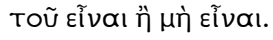

supremos. Para excluir tais termos, Patzig se pronuncia de modo muito breve e pouco esclarecedor: "categories (on Aristotle's definition) do not satisfy axiom (2)". Além disso, as ocorrências de "substância" e "unidade", em Pr. An. I 5, 27a 19-20 e 27b 6-8, também são ignoradas, talvez em decorrência de estarem associadas a pares de premissas inconcludentes.

21 Ver, por exemplo, os silogismos formulados em Pr. An. II 15.

Manuscrito - Rev. Int. Fil., Campinas, v. 36, n. 1, p. 5-48, jan.-jun. 2013. 
Chamo 'termo' aquilo no que a proposição se dissolve, ou seja, o item que se predica e o de que se predica, acrescentando 'é' ou 'não é' (24b 16-18).

Esse pronunciamento é muito vago e, em decorrência, pouco revelador. Por isso, em relação à presente investigação, tal capítulo quase não oferece material que possa ser aproveitado. É claro que não é bem essa a opinião de nossos interlocutores. Ross, Lukasiewicz e Patzig conceberam o mero fato de Aristóteles não ter feito menção a termos singulares no capítulo 1 de Primeiros Analíticos I como forte evidência de que tais termos não teriam lugar na silogística ${ }^{22}$.

Essa atitude nos parece incorreta. $\mathrm{O}$ fato de não encontrarmos ali qualquer menção a termos singulares revela apenas que o capítulo não tem aptidão para contribuir com a investigação. Poder-se-ia alegar, talvez, que a exposição das proposições silogísticas, no trecho $24 \mathrm{a}$ 16-22, é exaustiva, de modo que a exclusão dos termos singulares fosse assegurada pelo simples fato de não haver alusão explícita às proposições que lhes são correlatas. Porém, o referido trecho cai em certo descrédito por envolver certas imprecisões, das quais o silêncio sobre as proposições singulares seria apenas mais uma. A diferença entre proposições particulares e indefinidas, por exemplo, é bem precária. Com efeito, a proposição particular "algum prazer não é bem" não é mais informativa que a proposição indefinida "prazer não é bem". Tanto em um caso quanto em outro, a relação que os termos possuem entre si é igualmente indeterminada, ou seja, não sabemos se (i) todo prazer não é bem ou se (ii) algum prazer não é bem e algum prazeré bem ${ }^{23}$.

${ }^{22}$ Ross (1949, p. 384), Lukasiewicz (1951, chapter 1, $\$ 1$, p. 1, $\$ 2$, p. 4), Patzig (1959, chapter 1, \$3, p. 5).

${ }^{23}$ Entre os comentadores, Ross (1949, p. 314) parece assumir que, no trecho 29a 27-29, Aristóteles teria feito uma declaração explícita de que tais proposições seriam de fato equivalentes. Bochenski (1951, p. 43), por sua vez, reconhece a referida passagem como evidência incontestável de que Aristóteles concebia tais proposições como intercambiáveis, o que torna a distinção 
Imprecisões como essa revelam o caráter provisório do trecho $24 \mathrm{a}$ 16-22. Por isso, essa passagem não pode ser considerada como resposta definitiva ao problema de saber se a silogística reserva lugar para termos singulares, sobretudo se a razão alegada para assim considerá-la for o mero fato de não encontrarmos ali qualquer menção a proposições singulares. Em certa medida, os comentadores perceberam que não poderiam recorrer apenas ao primeiro capítulo de Primeiros Analíticos I para decidir a questão e estenderam a discussão ao capítulo 27, tomando uma decisão bastante acertada, porque é nesse capítulo que Aristóteles apresenta sua conhecida tripartição de entes e os compreende claramente como fatores de atribuição, suscetíveis de articulação silogística. $\mathrm{O}$ trecho 43a 25-43 oferece três tipos de termos e, como bem observaram os proponentes das opiniões tradicionais, impõe certas restrições ao uso de termos de natureza singular, bem como ao uso de termos de alto grau de generalidade - quer sejam summa genera, como prefere Ross, ou transcategoriais ("ente" e "um"), como entende Lukasiewicz. O que escapou a nossos interlocutores é que essas restrições estão longe de expulsar da silogística qualquer dos três tipos de termos ali apresentados. Por isso, em defesa de nossa posição, propomos reexaminar o trecho 43a 25-43, pois entendemos que o texto por si só não deixa dúvidas de que nenhum dos três tipos de termos introduzidos na referida passagem tenha sido excluído da silogística.

Assim, examinemos o famoso texto que tem alimentado a discussão sobre termos silogísticos:

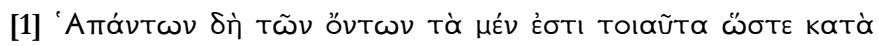

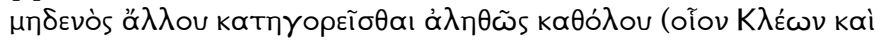

proposta no primeiro capítulo um tanto despropositada. Lukasiewicz (1951, \$2, p. 5) também reconhece que Aristóteles trata tais proposições como intercambiáveis, mas não admite que Aristóteles tenha se pronunciado de modo explícito a respeito dessa equivalência, preferindo delegar esse feito a Alexandre.

Manuscrito - Rev. Int. Fil., Campinas, v. 36, n. 1, p. 5-48, jan.-jun. 2013. 


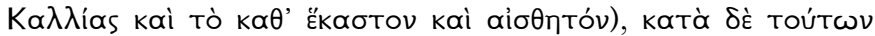

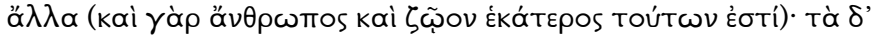

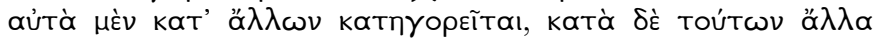

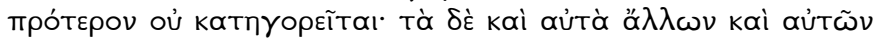

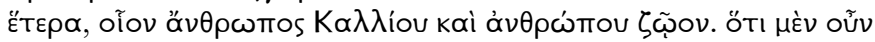

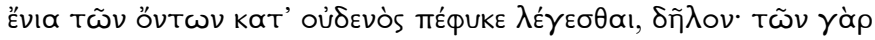

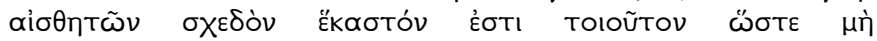

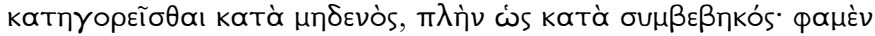

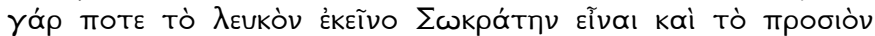

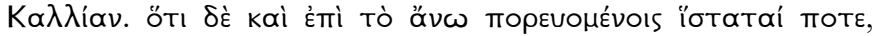

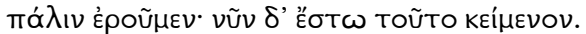

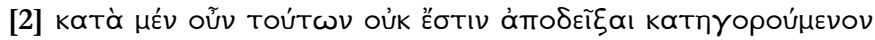

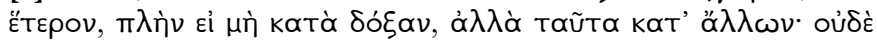

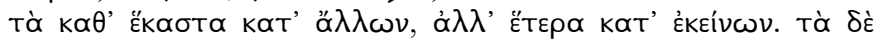

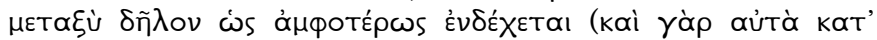

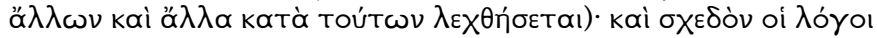

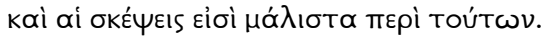

[1] Entre todos os entes, alguns são tais que não se afirmam de nenhum outro verdadeiramente como universais (por exemplo, Cleon e Cálias, ou seja, o particular e o sensível), mas outros se afirmam deles; de fato, cada um desses é tanto homem quanto animal. Alguns são eles próprios afirmados de outros, mas nenhum outro anterior se afirma deles. Alguns são eles próprios afirmados de outros e outros são afirmados deles; por exemplo, homem, que se afirma de Cálias e do qual animal se afirma. Assim, é evidente que certas coisas, por natureza, não se dizem de nenhuma outra; de fato, em geral, entre as coisas sensíveis, cada uma é tal que não se afirma de nenhuma outra, a não ser por acidente; com efeito, às vezes dizemos que aquele branco é Sócrates e que aquele que se aproxima é Cálias. (Ainda diremos por que também para cima, em algum momento, a série se interrompe. Mas por ora seja assumido isso).

[2] Assim, acerca dessas coisas, não é possível demonstrar outra sendo afirmada (a não ser segundo opinião), mas é possível demonstrar elas próprias sendo afirmadas de outras. Tampouco é possível demonstrar as coisas particulares sendo afirmadas de outras, mas é possível demonstrar outras sendo afirmadas delas. Já das coisas que ficam entre essas, é evidente que é possível demonstrar afirmando de ambos os modos; pois tanto elas serão ditas de outras quanto outras serão ditas delas. Grosso modo, os argumentos e as investigações são, sobretudo, acerca dessas coisas (43a 25-43).

Manuscrito - Rev. Int. Fil., Campinas, v. 36, n. 1, p. 5-48, jan.-jun. 2013. 
A mais natural divisão que podemos impor à passagem acima exige duas seções.

[1] Na primeira seção (43a 25-37), Aristóteles apresenta sua conhecida tripartição de entes, compreendidos como fatores de atribuição e classificados segundo as funções que cada classe de termos pode desempenhar em proposições destinadas a operações silogísticas. A passagem é inaugurada com um pronunciamento a respeito de todos os

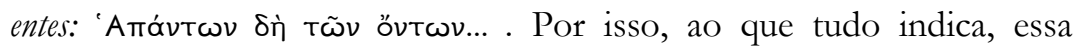
divisão tripartite é exaustiva e não deixa de fora nenhuma classe de termos. Os resultados provenientes dessa classificação trazem certas restrições à atuação de alguns termos na silogística: nas linhas 25-29, Aristóteles nega que os termos de natureza singular (тò $k \alpha \theta^{\prime}$ '̌k $\alpha \sigma \tau \alpha$ )

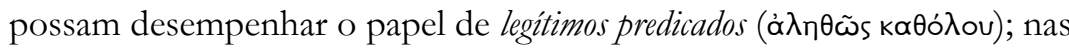
linhas 29-30, rejeita a possibilidade de atribuir aos termos de alta generalidade um termo que lhes seja anterior (про́тєроv). Conforme já o dissemos, essas restrições passam longe da exclusão de qualquer das classes de termos apresentadas no referido trecho do capítulo 27. A principal evidência disso aparece na imediata seqüência do texto, em que Aristóteles avalia os efeitos dessas restrições sobre as demonstrações. Isso nos leva à segunda seção.

[2] $\mathrm{Na}$ segunda seção (43a 37-43), são explicitadas as conseqüências que as restrições apresentadas na seção anterior (43a 25-37) produzirão nas demonstrações ${ }^{24}$. Nas linhas 37-39, Aristóteles se pronuncia a respeito dos termos de alta generalidade (summa genera

${ }^{24}$ É bem verdade que, em relação ao cenário que temos em Segundos Analíticos I 2 , a noção de apodeixis que aparece no capítulo 27 ainda exige muitos aperfeiçoamentos, mas não nos parece justo entendê-la meramente como prova silogística, já que ela envolve exigências de ordem atributiva que restringem as provas denotadas pela noção de apodeixis assumida no capítulo a um subgrupo da noção mais geral de silogismo. As provas silogísticas formuladas em Primeiros Analiticos II 15, por exemplo, ficam de fora do grupo de silogismos dos quais o capítulo 27 pretende dar conta. Assim sendo, optamos por manter a tradução de apodeixis por "demonstração" e não por "prova".

Manuscrito - Rev. Int. Fil., Campinas, v. 36, n. 1, p. 5-48, jan.-jun. 2013. 
e/ou transcategoriais): a possibilidade de demonstrar qualquer outro termo a respeito deles é recusada ${ }^{25}$, mas a de demonstrá-los a respeito de outros termos é afirmada textualmente. Nas linhas 39-40, o pronunciamento se faz a respeito dos termos de natureza singular (tò $\kappa \alpha \theta^{\prime}$ ék $\left.\alpha \sigma \tau \alpha\right)$ : a possibilidade de demonstrá-los a respeito de outros termos é recusada, mas a de demonstrar outros termos a respeito deles também é afirmada. Nas linhas 40-42, Aristóteles trata dos termos de generalidade intermediária (т⿳亠㐅 $\mu \varepsilon т \alpha \xi \dot{\text { ) }}$ e não lhes impõe nenhuma restrição: é possível demonstrá-los a respeito de outros termos, bem como é possível demonstrar outros termos a respeito deles ${ }^{26}$.

Por fim, nas linhas 42-43, Aristóteles encerra a passagem com um pronunciamento de caráter geral e conclusivo, pronunciamento que, ao contrário do que Ross sugeriu e, mais tarde, Lukasiewicz endossou, não nega absolutamente nada do que fora dito até então.

É claro que o leitor ainda pode levar em conta que Aristóteles só

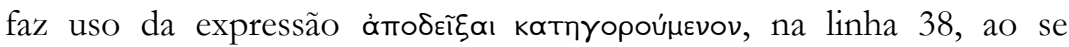
pronunciar a respeito dos termos de alta generalidade, e que, por isso, a pressuposição de tal expressão nos demais pronunciamentos seria artificiosa e desqualificaria a tradução e a leitura que propomos. De fato, essa expressão causou incômodo a alguns tradutores de língua inglesa, influenciados provavelmente pelos legados de Ross e Lukasiewicz. A. J. Jenkinson e Robin Smith, por exemplo, traduzem a

\footnotetext{
${ }^{25} \mathrm{Na}$ verdade, Aristóteles reconhece uma exceção, aludindo à possibilidade de

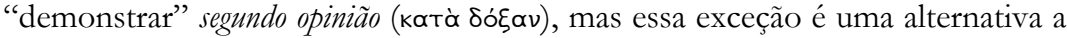
ser evitada.

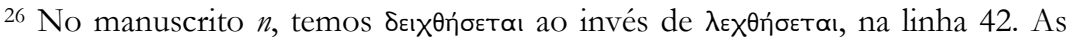
duas alternativas favorecem a nossa leitura. Optamos pela manutenção de $\lambda \varepsilon x \theta$ ńбetaı para não perder a relação explicativa que há entre os pronunciamentos das linhas 40-41, de um lado, e 30-32, de outro. De fato,

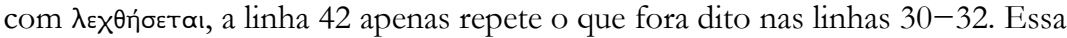
opção revela que as linhas 30-32 explicam a linha 42 e sugere que a mesma relação explicativa ocorra entre as linhas $25-29$ e 39-40, bem como entre as linhas 29-30 e 37-39.
} 


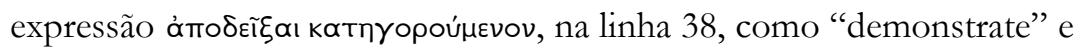
"demonstrate to be predicated", respectivamente. No entanto, ambos evitam tal tradução nas linhas subseqüentes, nas quais a expressão não aparece de modo explícito, e substituem "demonstrate" por "predicate" 27.

Há pelo menos uma boa razão para rejeitar tais traduções: elas assumem que, na segunda seção (43a 37-43), precisamente no que diz respeito às conseqüências que as restrições introduzidas na primeira seção (43a 25-37) têm sobre as demonstrações, Aristóteles estaria interessado apenas nos termos de alta generalidade, dado que recorre à

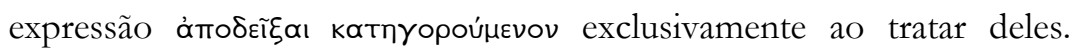

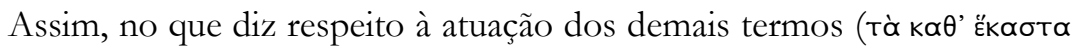
e Tà $\mu \varepsilon \tau \alpha \xi \grave{y})$ nas demonstrações, Aristóteles já não teria a pretensão de avaliar as conseqüências dessas restrições, limitando-se apenas a repetir o que fora dito na primeira seção. Essa leitura impõe ao texto uma interrupção não muito natural em seu desenvolvimento e ainda o torna redundante, sem apresentar uma razão satisfatória que justifique essa leitura.

\footnotetext{
${ }^{27} \mathrm{Na}$ linha 39, por exemplo, A. J. Jenkinson (in Barnes, 1984) traduz à $\lambda \lambda \grave{\alpha}^{\circ}$

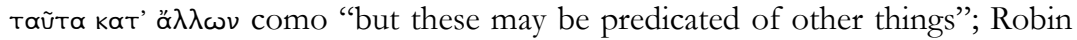
Smith vai na mesma direção e traduz como "but they are predicated of others", embora reconheça em seu comentário ao trecho 43a 40ss., na página 50 (comentário que, na verdade, trata da linha 39) que a frase pode ser traduzida como "other things are demonstrated to be predicated of them"; nas

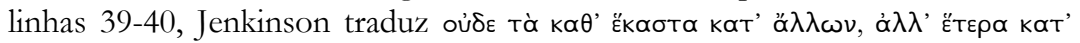

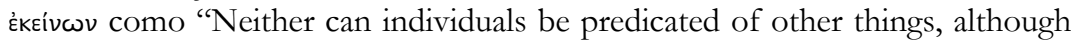
other things can be predicated of them"; Robin Smith não destoa disso e traduz como "Neither can individuals be predicated of other things, but instead other things are predicated of them"; por fim, nas linhas 40-41,

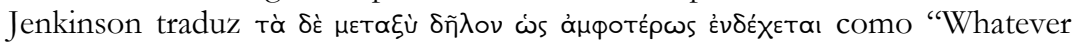
lies between these limits can be spoken of in both ways", ao passo que Robin Smith traduz como "But it is clear that for those in between, predication is possible in both ways".
}

Manuscrito - Rev. Int. Fil., Campinas, v. 36, n. 1, p. 5-48, jan.-jun. 2013. 
Na contramão de A. J. Jenkinson e Robin Smith, temos Mario

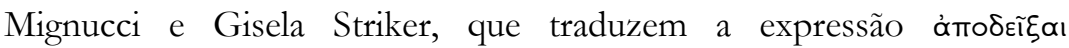

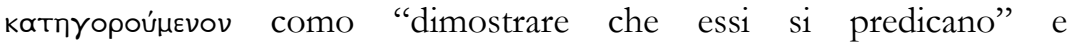
"demonstrate to be said of", respectivamente, e entendem as linhas 39-41 como pronunciamentos nos quais, embora não apareça de modo explícito, a expressão ainda está em jogo ${ }^{28}$. Essas traduções certamente são as mais fiéis ao texto grego e corroboram a tradução e a interpretação que propomos, justificando o abandono da leitura tradicional sugerida por Ross e cristalizada nos estudos de Lukasiewicz. A essa altura, já podemos fazer um balanço dos resultados que o capítulo 27 do Livro I de Primeiros Analiticos de fato nos impõe. O cenário que se desenha é o seguinte:

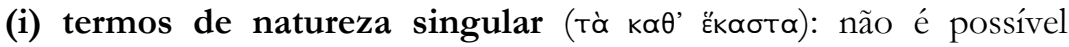

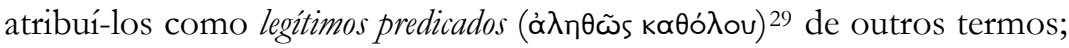
por isso, tampouco é possível demonstrá-los a respeito de outros termos; no entanto, é possível lhes atribuir outros termos como legítimos

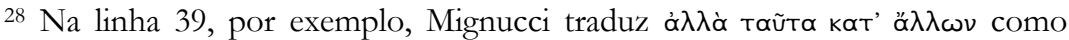
"mentre è possibile dimostrare che essi si predicano di altri”; Striker, por sua vez, traduz como "but [sc. one can demonstrate] only that they themselves are predicated of other things"; na linha 40, ambos fazem questão de recuperar a

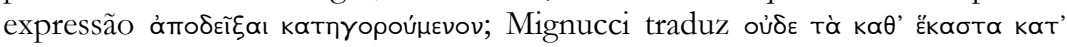

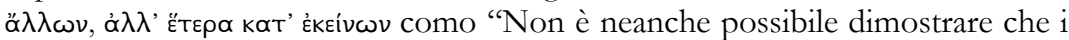
singolari si predicano di altre cose, ma soltanto che altre cose si predicano di essi"; Striker segue a mesma linha e traduz como "nor can one demonstrate that individuals are said of other things, but only that other things are said of them". $\mathrm{Na}$ linha 41, por sua vez, a expressão é recuperada novamente e o trecho tà $\delta \dot{\varepsilon}$

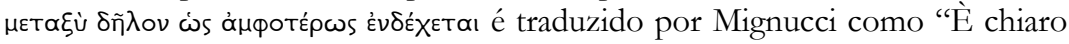
invece che le cose intermedie è possibile dimostrarle nei due modi", ao passo que, por Striker, como "But clearly the intermediate things admit [sc. to be demonstrated] of both".

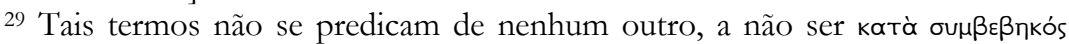
(43a 33-35).

Manuscrito - Rev. Int. Fil., Campinas, v. 36, n. 1, p. 5-48, jan.-jun. 2013. 
predicados; por conseguinte, também é possível demonstrar outros termos a respeito deles (conferir 43a 25-29 e 39-40);

(ii) termos de alta generalidade (summa genera e/ou tà mãoıv

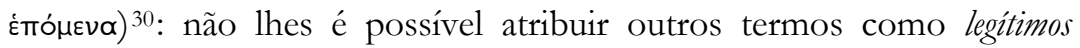
predicados - de fato, não há termo anterior (тро́тєроu) que lhes possa ser atribuído; por isso, tampouco é possível demonstrar outros termos a respeito deles; no entanto, é possível atribuí-los como legítimos predicados de outros termos; logo, também é possível demonstrá-los a respeito de outros termos (conferir 43a 29-30 e 37-39);

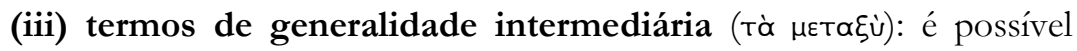
atribuí-los como legítimos predicados de outros termos, bem como lhes atribuir outros termos como legítimos predicados; em razão disso, também é possível demonstrá-los a respeito de outros termos, bem como demonstrar outros termos a respeito deles (conferir 43a 30-32 e 40-42).

Assim, o que prevalece é que Aristóteles jamais afastou de sua lógica qualquer das três classes de termos apresentadas em Primeiros Analíticos I 27, muito embora tenha endereçado certas restrições atributivas a algumas delas.

\section{Primeiros Analíticos I 28 e os Axiomas de Patzig}

Patzig parece entender que o capítulo 27 não é merecedor de toda a atenção que lhe foi concedida por Ross e Lukasiewicz. O capítulo 28, em sua opinião, é bem mais promissor no que diz respeito à questão de saber sobre quais termos a silogística opera ${ }^{31}$, enquanto o capítulo 27

30 Como Aristóteles não oferece exemplos de termos desse tipo, deixamos indeterminado se são summa genera, como propõe Ross, ou transcategoriais de generalidade total (“ente" e "um"), como prefere Lukasiewicz (cf. nota 3).

31 Patzig (1959, §3, p. 6).

Manuscrito - Rev. Int. Fil., Campinas, v. 36, n. 1, p. 5-48, jan.-jun. 2013. 
serviria mais como discussão preparatória para os assuntos tratados no capítulo seguinte.

De fato, há forte unidade entre esses textos. O objetivo predominante que os vincula e orienta é anunciado no início do capítulo 27 e consiste em mostrar "de que modo sempre estaremos providos de silogismos em relação ao que for proposto e por qual via alcançamos os princípios de cada coisa" 32 . O capítulo 27 contribui com esse objetivo na medida em que faz recomendações sobre como selecionar termos e premissas e classifica os fatores silogísticos segundo as funções (sujeito e predicado) que podem desempenhar de modo irrestrito em proposições silogísticas. A contribuição do capítulo 28, por sua vez, está associada aos procedimentos de prova de cada uma das quatro formas proposicionais categóricas ( $a, e, i$ e o). Esses procedimentos são caracterizados basicamente pela descrição dos parâmetros de localização do fator capaz de mediar os extremos (тó ăkpa) na relação categórica acarretada na conclusão. Trata-se, portanto, de procedimentos de busca e localização do termo mediador (тò $\mu \varepsilon ́$ ćov).

Assim, para provar, por exemplo, a relação universal afirmativa EaA, prescreve Aristóteles, devemos encontrar um fator comum a duas listas: (i) aquela de termos aos quais o extremo maior $A$ se atribui universalmente e (ii) aquela de termos que se atribuem universalmente ao extremo menor $E^{33}$. O resultado será o mediador $M$, tal que $M a A$ e $E a M$, o que perfaz um silogismo em Barbara. Semelhantemente, para provar a relação particular afirmativa EiA, Aristóteles recomenda a localização de um elemento comum às listas de (i) termos aos quais o extremo maior $A$ se atribui universalmente e de (ii) termos aos quais o extremo menor $E$ se atribui universalmente, ou seja, às listas de termos

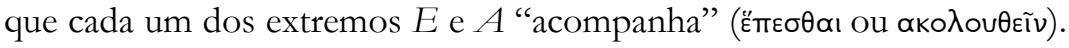
Nesse caso, o termo comum $M$ será tal que $M a A$ e $M a E$, o que nos

\footnotetext{
32 An. Pr. I 27, 43a 20-21.

33 An. Pr. I 28, 43b 39-43.
}

Manuscrito - Rev. Int. Fil., Campinas, v. 36, n. 1, p. 5-48, jan.-jun. 2013. 
permite concluir EiA por Darapti (terceira figura) ${ }^{34}$. Por sua vez, a prova da relação universal negativa Ee $A$ também se valerá da identificação de um fator comum às listas de (i) termos contrários a um extremo e de (ii) termos que se atribuem universalmente ao outro extremo: se o mediador $M$, comum às duas listas, for contrário ao extremo maior $A \mathrm{e}$ universalmente atribuído ao extremo menor $E$, o mediador $M$ será tal que $M e A$ e $E a M$ ou $A e M$ e EaM, possibilitando a prova de $E e A$ (respectivamente) por Celarent e por Cesare; mas se o mediador $M$ for contrário ao extremo menor $E$ e universalmente atribuído ao extremo maior $A, M$ será tal que $A a M$ e $E e M$, restringindo a prova de $E e A$ a Camestres $^{35}$. Por fim, para provar a relação particular negativa Eo $A$, Aristóteles recomenda a localização de um fator comum às listas de (i) termos contrários ao extremo maior $A$ e de (ii) termos aos quais o extremo menor $E$ se atribui universalmente. Assim, o mediador $M$ será tal que $M e A$ e $M a E$, o que prova Eo $A$ por Felapton ${ }^{36}$.

Em todas as recomendações do capítulo 28, Aristóteles se orienta pelas conclusões almejadas, propondo, a partir delas, procedimentos de busca e localização dos fatores capazes de acarretar cada uma das possíveis relações categóricas. A estratégia de Aristóteles, portanto, não consiste em partir de premissas e deduzir os resultados que delas se seguem, mas, fazendo o caminho inverso, consiste em partir da conclusão e buscar o termo mediador capaz de articular os extremos na relação categórica $(a, e, i$ ou $o)$ da conclusão.

Por não captar a natureza invertida dessa estratégia, Patzig não compreendeu plenamente o que Aristóteles propusera e julgou que o capítulo 28 , muito mais que o capítulo 27 , impunha severas restrições à lista de termos capazes de figurar em silogismos aristotélicos. $\mathrm{Na}$ verdade, o capítulo 28 nem sequer trata da questão de saber sobre quais termos a silogística opera, mas limita-se a descrever os parâmetros de

\footnotetext{
34 Ibidem, 43b 43-44a 2.

35 An. Pr. I, 44a 2-8.

36 An. Pr. I 28, 44a 9-11.

Manuscrito - Rev. Int. Fil., Campinas, v. 36, n. 1, p. 5-48, jan.-jun. 2013.
} 
localização do mediador de cada forma categórica. É claro que, ao descrever esses parâmetros, Aristóteles acaba por assumir certos pressupostos que, em último caso, podem ter algum efeito sobre a lista de termos que integram o domínio de operação da silogística. Ainda assim, é preciso observar que as recomendações apresentadas no capítulo 28 são pensadas em relação à prova de cada proposição categórica em particular. Por isso, os pressupostos envolvidos nessas recomendações, bem como as eventuais restrições de termos que lhes sejam correlatas, deverão ter aplicação circunscrita a cada caso, isto é, aos procedimentos de prova de cada conclusão em particular.

Patzig parece não ter dado a devida atenção a esse detalhe, pois, embora compreenda os seus axiomas como pressupostos implícitos das recomendações de Aristóteles - recomendações cuja aplicação está circunscrita a cada caso - Patzig os assume como válidos para termos de todo e qualquer silogismo ${ }^{37}$. No entanto, é flagrante que certos silogismos não dependem de alguns de seus axiomas. Um arquetípico silogismo em Barbara, por exemplo, funciona perfeitamente bem sem pressupor, para qualquer de seus termos, a validade do terceiro axioma, isto é, sem pressupor que exista para qualquer de seus termos (ou mesmo para qualquer de seus extremos, para ser fiel ao capítulo 28) um termo que lhe seja "contrário".

Ao que tudo indica, o que levou Patzig a estender a validade de seus axiomas sobre todos os silogismos é o trecho 44a 12-17, em que Aristóteles estipula letras para as listas de termos com as quais pretende trabalhar na exposição dos procedimentos de prova $^{38}$. $\mathrm{Na}$ referida passagem, Aristóteles considera basicamente três tipos de termos, que se distinguem pelo termo extremo que lhes é correlato, bem como pela relação predicativa que cada um mantém com esse extremo. Para cada extremo, Aristóteles estipula (i) termos que lhe são atribuidos universalmente, (ii) termos aos quais ele próprio se atribui universalmente e (iii) termos que não lhe

\footnotetext{
${ }^{37}$ Patzig (1959), §3, p. 6-7.

38 An. Pr. I 28, 44a $12-17$.
}

Manuscrito - Rev. Int. Fil., Campinas, v. 36, n. 1, p. 5-48, jan.-jun. 2013. 
podem ser atribuidos. Os termos de primeiro tipo devem ter servido de estímulo para a necessidade de termos superordenados próprios que é marca do segundo axioma de Patzig; os termos de segundo tipo, por sua vez, para a necessidade de termos subordinados próprios, marca do primeiro axioma; os de terceiro, por fim, para a necessidade de termos "contrários", marca do terceiro axioma.

É bem verdade que os termos estipulados por Aristóteles envolvem certa analogia com os axiomas propostos por Patzig. Mas é preciso notar, em primeiro lugar, que nenhum dos procedimentos de prova descritos por Aristóteles depende da estipulação dos três tipos de termos ${ }^{39}$. A recomendação de prova da proposição particular afirmativa, por exemplo, requer apenas (ii) termos aos quais os extremos se atribuem universalmente ${ }^{40}$. O fato de Aristóteles já estipular, de antemão, três tipos de termos para cada extremo, não torna obrigatório que todo e qualquer extremo (e muito menos que todo e qualquer termo silogístico, como prefere Patzig), independentemente do silogismo a que pertença, dependa dos três tipos de termos estipulados, precisamente porque a estipulação desses termos está ancorada em um par de extremos que é muito peculiar. Esse par de extremos é pensado com propósitos didáticos, orientados à exposição dos procedimentos de prova de cada uma das possíveis relações categóricas $(a, e, i$ e $o$ ). Trata-se de um par de extremos que, em benefício da exposição, é assumido como articulável em qualquer das relações categóricas. Porém, essa assunção só faz sentido no contexto preciso dessa exposição de procedimentos de prova, afinal, algumas dessas relações categóricas são incompatíveis entre si - por exemplo, as relações universal afirmativa e particular negativa. Por isso, devemos presumir que as estipulações de termos que lhes dão suporte também o são e, portanto, não podem valer em conjunto e para todos os casos.

\footnotetext{
${ }^{39}$ Idem, 44a 17-30.

40 Ibidem, 44a 19-21.

Manuscrito - Rev. Int. Fil., Campinas, v. 36, n. 1, p. 5-48, jan.-jun. 2013.
} 
Para esclarecer esse ponto, retomemos rapidamente os procedimentos de prova das proposições universal afirmativa e particular negativa ${ }^{41}$. Assumindo um mesmo par de extremos, como faz Aristóteles, estaremos diante de proposições contraditórias (EaA e EoA). Dado que tais proposições são incompatíveis, as condições das quais elas são provenientes também o serão. Dizendo de outro modo, a localização de um termo comum entre (i) termos aos quais o extremo maior se atribui universalmente e (ii) termos que se atribuem universalmente ao extremo menor é incompatível com a localização de um termo comum entre (i') termos aos quais o extremo maior não pode ser atribuido e (ii') termos aos quais o extremo menor se atribui universalmente. Assim, em presença das condições de prova de uma das proposições incompatíveis, as condições da outra poderão ser dispensadas, já que são condições requeridas para uma prova cuja possibilidade já não existe. E não há razão para manter os termos estipulados e dispensar apenas a possibilidade de um termo comum entre as listas, pois ambos os pressupostos são requisitados para servir um único e mesmo propósito, o de estabelecer condições para a prova da relação categórica que se pretende obter. Não há uma razão que justifique a manutenção das listas de termos estipulados em detrimento da possibilidade de um termo comum entre as listas, pois o propósito que introduz uma exigência também introduz a outra. Sob essa perspectiva, fica claro que os termos estipulados no trecho $44 \mathrm{a}$ 12-17 não podem ser pressupostos indispensáveis de quaisquer termos silogísticos, tampouco pressupostos que devem ser satisfeitos em conjunto por termos de todo e qualquer silogismo. Afinal, Aristóteles estipula cada uma das listas supondo que seus termos serão candidatos à função de mediador (e não à função de termos silogísticos) e o faz segundo as exigências específicas envolvidas na prova de cada relação categórica em particular ( $a, e, i$ ou $o$ ). Compreender tais listas como pressupostos

${ }^{41}$ An. Pr. I 28, 43b 39-43 e 44a 9-11.

Manuscrito - Rev. Int. Fil., Campinas, v. 36, n. 1, p. 5-48, jan.jun. 2013. 
que devem ser satisfeitos por todo e qualquer termo silogístico é um equívoco.

Em segundo lugar, o capítulo 28 não parece estar orientado propriamente à prova silogística das formas categóricas, mas, em algum sentido, à demonstração de tais relações. Há indícios que sugerem essa leitura. O principal deles talvez seja o fato de Aristóteles se mostrar interessado em localizar um meson que fica no meio do caminho entre um mediador que satisfaz requisitos meramente dedutivos e um mediador que supera tais requisitos e se configura como um fator explanatório em uma legítima demonstração cientifica ${ }^{42}$. Retomemos, por exemplo, as recomendações de prova das proposições particulares ( $i$ e o). Em 43b 43-44a 2, Aristóteles recomenda a prova de EiA por premissas universais, conduzindo a prova a um silogismo em Darapti, embora admita a possibilidade de concluir proposições particulares a partir de um par de premissas em que apenas uma é universal (41b 22-27). Em 44a 9-11, a exemplo do que ocorre com a prova de EiA, Aristóteles recomenda a prova de Eo $A$ novamente por premissas universais, desta vez, conduzindo a prova a um silogismo em Felapton. Essas duas recomendações de prova pressupõem que o meson requisitado para a prova não é um mediador meramente dedutivo, mas um mediador que se articula com os extremos exclusivamente por relações universais. É claro que esse cenário ainda está muito distante daquele que temos, por exemplo, no capítulo 2 do Livro II de Segundos

42 Em uma demonstração científica, não basta que o mediador se relacione com os extremos de tal modo que a dedução da conclusão esteja formalmente assegurada. Aristóteles ainda exige que o mediador satisfaça certos requisitos não formais. O principal deles é o de explicar adequadamente por que o extremo maior se atribui ao extremo menor (Angioni, 2007). Em Segundos Analíticos I 13, por exemplo, essa diferença (entre um mediador que satisfaz exigências meramente dedutivas e um mediador que funciona como explicação do fato relatado na conclusão) é utilizada como critério básico para distinguir o conhecimento de que $C$ é $A$ (conhecimento do fato) e o conhecimento de por que $C$ é $A$ (conhecimento da causa).

Manuscrito - Rev. Int. Fil., Campinas, v. 36, n. 1, p. 5-48, jan.-jun. 2013. 
Analíticos (90a 6-7), em que o meson é pensado como a causa que explica por que a relação dada entre os extremos, explicitada na conclusão da demonstração, é o caso. Mesmo assim, temos o suficiente para mostrar que Aristóteles não está levando em conta todos os silogismos de seu sistema lógico, mas apenas aqueles nos quais ambas as premissas são universais. Por que razão exatamente Aristóteles faz essa escolha é algo a se investigar. O que nos importa é que essa escolha restringe o escopo do capítulo a um grupo específico de silogismos, o que não é compatível com a validade irrestrita dos axiomas propostos por Patzig.

Em terceiro lugar, Aristóteles não lida com as noções de subordinação própria, superordenação própria e contrariedade, mas prefere (i)

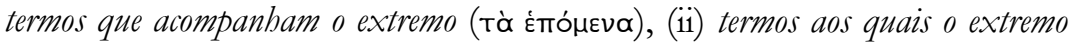
acompanha (oĩs aủtò Ëாєтaı) e (iii) termos que não podem ser atribuídos ao

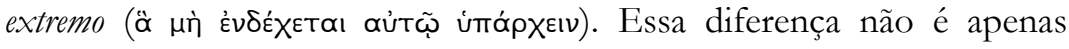
terminológica, mas conceitual. As relações de subordinação e superordenação próprias pressupõem termos que não são coextensivos: se $X$ é um termo subordinado próprio de $Y, X a Y$ é o caso, mas $Y a X$, não; se $Z$ é um termo superordenado próprio de $Y, Y a Z$ é o caso, mas $Z a Y$, não. $\mathrm{O}$ próprio Patzig reconhece essas conseqüências ao formular os seus dois primeiros axiomas ${ }^{43}$. Aristóteles, no entanto, ao se valer das relações de "acompanhamento" entre os termos, não hesita em rejeitá-las. No capítulo 29, por exemplo, Aristóteles menciona a possibilidade de provar

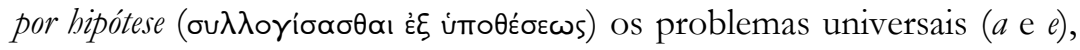
assumindo precisamente a possibilidade de coextensão entre os termos envolvidos, possibilidade da qual Patzig parece prescindir ao formular seus axiomas. A passagem à qual nos referimos é a seguinte:

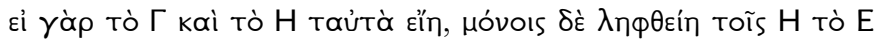

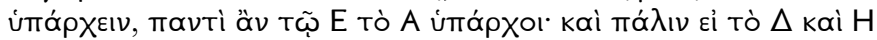

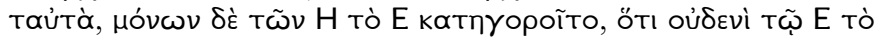
A úmóp̧દl.

${ }^{43}$ Patzig (1959, §3, p. 6-7).

Manuscrito - Rev. Int. Fil., Campinas, v. 36, n. 1, p. 5-48, jan.-jun. 2013. 
Com efeito, se $C$ e $G$ fossem o mesmo, mas se assumisse que $E$ se atribui apenas aos $G$ 's, $A$ se atribuiria a todo $E$. Novamente, se $D$ e $G$ fossem o mesmo, mas $E$ se afirmasse apenas dos $G$ 's, $A$ se atribuirá a nenhum $E$ (45b 24-27).

Em 44a 12-17, Aristóteles já havia estipulado que a letra $C$ representaria um termo ao qual o extremo maior $A$ acompanha, ou seja, ao qual se atribui universalmente; também foi estipulado que a letra $G$ representaria um termo ao qual o extremo menor E acompanha, ou seja, ao qual se atribui universalmente; por fim, ainda ficou decidido que a letra $D$ representaria um termo que não pode ser atribuido ao extremo maior $A$. Assim, a identidade entre $C$ e $G$, a exemplo do que ocorre em 44a 19-21, conduz a prova de EiA a um silogismo em Darapti, ao passo que a identidade entre $D$ e $G$, a exemplo do que ocorre em 44a 28-30, conduz a prova de Eo $A$ a um silogismo em Felapton ${ }^{44}$. No entanto, nessa passagem, embora os procedimentos de prova das proposições particulares ( $i$ e $o$ ) sejam acionados, aquilo que se quer mostrar é de que

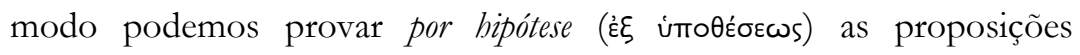
universais. Para alcançar esse resultado, Aristóteles assume que o extremo menor $E$ se atribui apenas (uóvov) a $G$, o que pode ser interpretado como uma maneira diferente de dizer que $E$ e $G$ são termos coextensivos. Sinal disso é o seguinte: ao assumir que $E$ se atribui apenas a $G$, Aristóteles se vê autorizado a concluir as proposições universais $E a A$ e $E e A$, o que só faz sentido sob o pressuposto de que $G$ e $E$ são termos coextensivos. De fato, sob tal pressuposto, a premissa menor $G a E$ pode ser "convertida" em $E a G$, o que transforma Darapti em Barbara, bem como Felapton em Celarent. Mas se os termos aos quais o extremo menor $E$ acompanha forem pensados como termos subordinados próprios de $E, G a E$ será o caso, mas $E a G$, não! Por conseguinte, tampouco as conclusões $E a A$ e EeA se seguiriam. Assim, se quisermos conferir sentido à passagem, temos que assumir que Aristóteles recorreu à possibilidade de construir silogismos com termos

${ }^{44}$ Darapti: CaA, GaE $\rightarrow \operatorname{Ei} A(C=G)$; Felapton: DeA, GaE $\rightarrow \operatorname{Eo} A(D=G)$.

Manuscrito - Rev. Int. Fil., Campinas, v. 36, n. 1, p. 5-48, jan.-jun. 2013. 
que são coextensivos; e, se assim for, podemos dizer que, para Aristóteles, a presença de silogismos cujos três termos são coextensivos em sua lógica não causava qualquer inconveniente ${ }^{45}$.

Segundo nos parece, as razões alegadas até aqui já são suficientes para mostrar que os axiomas de Patzig não podem servir como critérios delimitadores de termos silogísticos. Ainda assim, vale a pena examinar duas passagens que eventualmente poderiam ser invocadas contra a interpretação que propomos. Embora não sejam citadas pelos proponentes das opiniões tradicionais, não é difícil imaginar que elas tenham servido de inspiração para aqueles que defendem a exclusão dos termos transcategoriais "ente" e "um". De fato, à primeira vista, tais passagens podem nos levar a pensar que Aristóteles não guardou lugar para tais termos na silogística. No entanto, como veremos, isso só é verdade à primeira vista.

45 O capítulo 29 não é a única evidência de silogismos com termos coextensivos na silogística. No capítulo 5 do Livro II de Primeiros Analíticos, precisamente em 57b 35-58a 12, Aristóteles trabalha com silogismos cujos três termos são coextensivos. Por sua vez, no capítulo 22, em 67b 27-32, Aristóteles inicia o texto dizendo que a coextensão entre os termos extremos de um silogismo requer um mediador também coextensivo, o que revela, por parte de Aristóteles, plena consciência a respeito da existência de silogismos com tríades coextensivas. Nos Segundos Analíticos, o interesse de Aristóteles por demonstrações que envolvem termos coextensivos pode ser classificado como uma obsessão. Basta notar que a própria demonstração universal - aquela que é considerada por Aristóteles como cientifica no mais alto grau - tem como uma de suas principais características a coextensão entre os três termos do silogismo (cf. Seg. An. I 4, 73b 32-74a 3), o que revela o papel central das tríades coextensivas no projeto aristotélico que é inaugurado com a silogística e culmina nas demonstracões cientificas (Angioni, 2007). Em Segundos Analíticos I 13 e II 16, Aristóteles novamente recorre a termos coextensivos na formulação de silogismos. A nossa preferência pela passagem 45b 24-27 do capítulo 29 de Primeiros Analíticos se dá apenas com base em sua conexão indiscutível com o capítulo 28, no qual Patzig julga encontrar seus axiomas.

Manuscrito - Rev. Int. Fil., Campinas, v. 36, n. 1, p. 5-48, jan.-jun. 2013. 
Uma das passagens às quais nos referimos é aquela com a qual Aristóteles encerra o capítulo 27 de Primeiros Analíticos I. Vejamos o que diz Aristóteles:

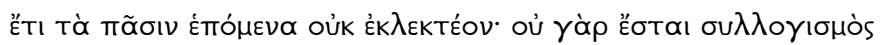

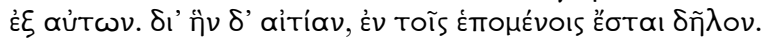

Além disso, não é preciso selecionar os itens que acompanham todas as coisas, pois não há silogismo a partir deles. A razão disso ficará evidente a seguir (43b 36-38).

Essa passagem trata dos termos transcategoriais de generalidade

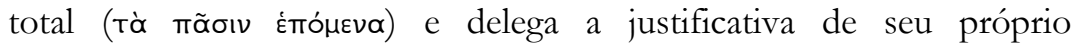
pronunciamento ao capítulo seguinte, no qual Patzig encontrou inspiração para seus axiomas. No capítulo 28, cumprindo o prometido, Aristóteles retoma esse assunto e reitera a impossibilidade de construir silogismos a partir de termos de generalidade total:



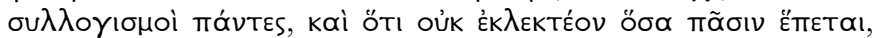

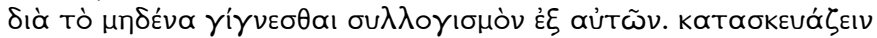

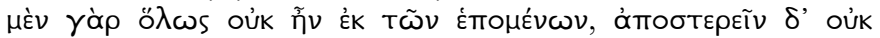

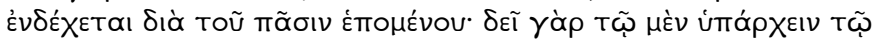

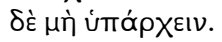

É evidente, então, que todos os silogismos vêm a ser através das figuras previamente mencionadas e que não é preciso coletar os itens que acompanham todas as coisas, porque nenhum silogismo vem a ser a partir deles. De fato, de modo algum é possível construir silogismo afirmativo a partir dos itens que acompanham, e não é possível construir silogismo negativo a partir do que acompanha todas as coisas, pois é preciso atribuir a um item e não atribuir ao outro (44b 19-24).

Fora de contexto e em uma leitura mais apressada, essas duas passagens podem nos levar a crer que a opinião tradicional que afasta da silogística os termos de generalidade total (como "ente" e "um") de fato encontra respaldo nos textos de Aristóteles. No entanto, mais uma vez, é preciso levar em conta que o capítulo 28 é marcado pela 
descrição de estratégias de localização de termos mediadores, e não de termos em geral. Dizendo de outro modo, Aristóteles não está interessado em localizar os termos que deverão encerrar a conclusão de um silogismo; pelo contrário, tais termos já estão plenamente determinados, bem como a relação proposicional $(a, e, i$ e $o$ ) que há entre eles, dado que a conclusão, na qual interagem, funciona como ponto de partida da investigação empreendida no capítulo. O que interessa para Aristóteles é a localização de termos mediadores e é nesse horizonte que tais passagens devem ser lidas. Assim, ao negar a possibilidade de construir silogismos a partir de termos transcategoriais de

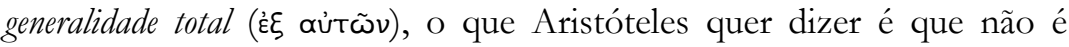
possível construir silogismos ${ }^{46}$ nos quais a função de mediador seja desempenhada por um termo desse tipo, razão pela qual, na busca pelo mediador, recomenda Aristóteles, "não é preciso coletar os itens que acompanham todas as coisas" (44b 20-21). Para justificar essa recomendação, Aristóteles apresenta duas razões: (i) "de modo algum é possível construir silogismo afirmativo a partir dos itens que acompanham" (44b 22-23); (ii) "não é possível construir silogismo negativo a partir do que acompanha todas as coisas, pois é preciso atribuir a um item e não atribuir ao outro" (44b 23-24). Na primeira razão, Aristóteles parece reconsiderar as listas de termos estipuladas no trecho 44a 11-17, pressupondo, ao que tudo indica, que os transcategoriais de generalidade total só podem figurar em listas de termos que acompanham os extremos. Isso se justificaria pela natureza inapta de tais termos para o papel de sujeito em proposições silogísticas, conforme se constata no capítulo I 27. Assim, na medida em que, nas provas afirmativas, a busca pelo mediador não envolve

\footnotetext{
${ }^{46} \mathrm{Na}$ verdade, como o escopo do capítulo 28 não abarca todo e qualquer silogismo, seria mais correto dizer que não é possível construir silogismos (nos quais se aprecia não apenas a conseqüência lógica entre premissas e conclusão, mas também a verdade das proposições envolvidas) assumindo um termo de generalidade total na função de mediador.
}

Manuscrito - Rev. Int. Fil., Campinas, v. 36, n. 1, p. 5-48, jan.-jun. 2013. 
apenas a lista de termos que acompanham um dos extremos, mas também a lista de termos aos quais um dos extremos acompanha (ver 43b 39-44a 2), os transcategoriais de generalidade total perdem a candidatura à função de mediador e já de saída nem sequer precisam ser $\operatorname{considerados}^{47}$. $\mathrm{Na}$ segunda razão, por sua vez, Aristóteles leva em conta o fato de que as provas negativas dependem de um mediador capaz de figurar em proposições universais negativas verdadeiras, exigência que não está no alcance dos termos de generalidade total. Afinal, se estamos diante de um transcategorial desse tipo, de antemão já assumimos a inexistência de um termo do qual ele não seja predicado. Assim, os termos de generalidade total ficam impedidos de serem atribuídos a um extremo e não atribuídos ao outro (44b 24), como deve ser o mediador de um silogismo negativo.

O que é verdade, portanto, é que Aristóteles dispensa os termos de generalidade total da função de mediador. De fato, quando se pretende construir silogismos nos quais se aprecia não apenas a conseqüência lógica entre premissas e conclusão, mas também a verdade das proposições envolvidas, tal como ocorre no capítulo 28, a busca do mediador entre transcategoriais de generalidade total é sempre infrutífera, porque só poderá devolver como resposta pretensos fatores de mediação, marcados por duas deficiências principais: a

\footnotetext{
47 Supomos que, em tais passagens, Aristóteles de fato tem em mente as recomendações de prova apresentadas no início do capítulo 28 , de modo que apenas os silogismos em Barbara e Darapti sejam considerados como silogismos afirmativos (cf. 43b 39-44a 2). Assim, entendemos que o pronunciamento das linhas 44b 22-23 se justificaria porque os termos de generalidade total, na prova de $a$, não podem integrar a lista de termos aos quais o extremo maior acompanha, bem como, na prova de $i$, a lista de termos aos quais ambos os extremos acompanham. No entanto, ainda que os demais silogismos afirmativos sejam levados em conta, o pronunciamento das linhas 44b 22-23 continua verdadeiro, já que Darii, Disamis e Datisi também exigem que o mediador esteja entre os termos aos quais o(s) extremo(s) acompanha (m).
}

Manuscrito - Rev. Int. Fil., Campinas, v. 36, n. 1, p. 5-48, jan.-jun. 2013. 
impossibilidade de desempenhar a função de sujeito de modo legítimo e a incapacidade de compor proposições negativas verdadeiras.

Nenhuma das passagens mencionadas acima (43b 36-38 e 44b 19-24) é citada - nem por Lukasiewicz, nem por Patzig - como evidência de que Aristóteles teria rejeitado os termos de generalidade total em seu sistema lógico. Porém, diante da escassez de evidências em favor da suposta exclusão de tais termos, não é insensato presumir que os proponentes dessa exclusão tenham encontrado inspiração nelas.

$\mathrm{Na}$ próxima seção, examinaremos textos nos quais Aristóteles constrói silogismos com termos de natureza singular. Veremos que o incômodo com a presença de tais termos na silogística é menos de Aristóteles e mais de seus intérpretes.

\section{Termos Singulares e o Silogismo Peripatético}

Já comentamos o fato de Lukasiewicz ter feito pesadas críticas à silogística, em especial ao suposto fato de Aristóteles ter afastado os termos de natureza singular de seu sistema lógico, o que seria, segundo Lukasiewicz, "o maior defeito" da lógica aristotélica ${ }^{48}$. Ao que parece, o responsável por levá-lo por esse caminho foi Ross, que tomou nota do também suposto fato de Aristóteles nunca se valer de nomes próprios e designações singulares em seus exemplos de silogismos ${ }^{49}$. Lukasiewicz reiterou a constatação de Ross (embora não o cite) e nela encontrou razão para não reconhecer como rigorosamente aristotélico o silogismo que qualificou pelo adjetivo "peripatético", silogismo formulado em primeira figura, com um nome próprio como sujeito da premissa menor e da conclusão.

De acordo com a tripartição de termos que pudemos conhecer no capítulo 27 de Primeiros Analíticos I (Seção II, Parte 1), não temos qualquer razão para expulsar da silogística os termos de natureza singular. É

\footnotetext{
${ }^{48}$ Lukasiewicz (1951, chapter 1, §3, p. 6).

${ }^{49}$ Ross (1949, p. 289, 384).

Manuscrito - Rev. Int. Fil., Campinas, v. 36, n. 1, p. 5-48, jan.-jun. 2013.
} 
claro que Aristóteles não deixa de lhes endereçar certas restrições; porém, vale a pena repetir, nenhuma das restrições introduzidas por Aristóteles no referido capítulo tem força suficiente para expulsar os termos singulares da lógica aristotélica. De fato, embora tais termos não possam figurar em proposições como legítimos predicados $(\dot{\alpha} \lambda \eta \theta \tilde{\omega} s$

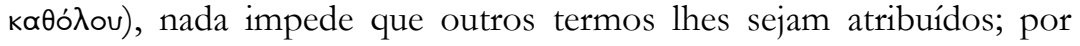
conseguinte, embora não possam ser demonstrados como legítimos predicados de outros termos, nada impede que outros termos sejam demonstrados como predicados deles ${ }^{50}$.

Fora dos Analíticos, já esbarramos em indícios que vão nessa direção. No capítulo 10 de Metafísica XIII (My), por exemplo, há uma breve passagem que sugere esse resultado. Enquanto argumenta em

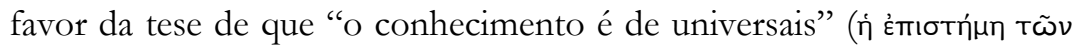
käódou), Aristóteles parece supor que os termos singulares "este triângulo" e "este homem" também são suscetíveis de operações silogísticas:

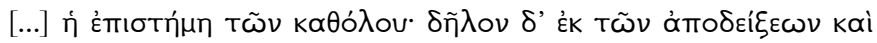

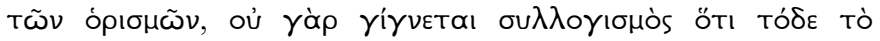

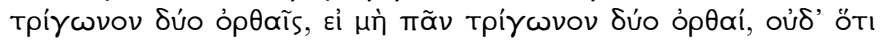

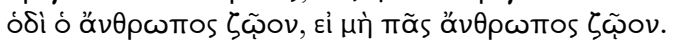

[...] o conhecimento é de universais: isso é evidente a partir das demonstrações e definições; de fato, não se produz silogismo de que este triângulo tem dois ângulos retos, a não ser que todo triângulo possua dois ângulos retos; tampouco de que este homem é animal, a não ser que todo homem seja animal (1086b 34-37).

Porém, essa passagem não é tão simples quanto pode parecer à primeira vista ${ }^{51}$. Paul Shorey, por exemplo, reprovaria já a tradução que

50 An. Pr. I 27, 43a 25-29 e 39-40. Ao comentar o capítulo 27, Mignucci (1969, p. 443) também reconhece a possibilidade "di costruire dimostrazioni e sillogismi anche relativamente a singolari", citando Alexandre, que também já a observa em seus comentários (An. Pr., p. 293, 13-23).

51 Shorey (1913).

Manuscrito - Rev. Int. Fil., Campinas, v. 36, n. 1, p. 5-48, jan.-jun. 2013. 
propomos, porque ela faz crer que Aristóteles estabelece uma relação de dependência dedutiva (silogística) entre proposições, dependência que de fato existe, mas da qual, para Shorey, a passagem em questão não trataria. De acordo com Shorey, as ocorrências de ei $\mu$ ǹ, nas linhas 33 e 36, não significam ' [...] 'unless', but is to be taken in its idiomatic sense as a virtual equivalent of á $\lambda \lambda \alpha^{\prime}$ ". Nesse caso, uma tradução mais fiel à posição de Shorey seria a seguinte:

[...] o conhecimento é de universais: isso é evidente a partir das demonstrações e definições; de fato, não se produz silogismo de que este triângulo tem dois ângulos retos, mas de que todo triângulo tem dois ângulos retos; tampouco de que este homem é animal, mas de que todo homem é animal (1086b 34-37).

Assim, o texto estabeleceria, não que as proposições singulares, no papel de conclusões silogísticas, são (dedutivamente) dependentes das proposições universais, mas que as conclusões propriamente silogísticas são universais (universalmente quantificadas) e não singulares.

Ross $^{52}$, ao tratar dessa passagem, não deixa de comentar a posição de Shorey:

He [Shorey] argues that in 1.33 knowledge is said to be 'of universals, i.e. to have universal conclusions as well as universal premises [...] and that singular propositions never occur as conclusions in Aristotle's logical writings.

$\mathrm{Na}$ verdade, Shorey ${ }^{53}$ não chega a dizer que proposições singulares nunca ocorrem como conclusões silogísticas nos escritos lógicos de Aristóteles, embora passe perto disso:

The syllogism with a particular ${ }^{54}$ conclusion is an inferior type (Analyt. Post. 79a 25ff.) [...]. Aristotle does not recognize singular proposition in his classification (Analyt. Priora A1; Grote, Aristotle, I, 205), and the

\footnotetext{
${ }^{52}$ Ross (1953, p. 464).

${ }^{53}$ Shorey (1913, p. 91).

${ }^{54}$ Nesse contexto, Shorey assume "particular" e "singular" como equivalentes.
}

Manuscrito - Rev. Int. Fil., Campinas, v. 36, n. 1, p. 5-48, jan.-jun. 2013. 
conclusion to an individual case interests him very little and is practically ignored.

Shorey tem alguma razão em alegar que os silogismos que concluem proposições singulares (também conhecidos como "peripatéticos") são de um tipo inferior, especialmente quando se leva em conta o horizonte das demonstrações científicas ${ }^{55}$, mas erra quando recorre ao trecho 79a 25ss. para dar base textual a tal alegação - o referido trecho nem mesmo trata desse assunto. Por sua vez e contra Shorey, Ross ${ }^{56}$ surpreende ao alegar o seguinte:

There are, however, occasional references in Aristotle to the occurrence of singular propositions as the minor premise or conclusion of syllogisms (e.g. An. Pr. 43a 37-40) [...].

55 Para Aristóteles, o silogismo dito científico no mais alto grau é a chamada demonstração universal. É importante notar que aqui o adjetivo "universal" tem um sentido muito preciso e não se justifica pela mera ocorrência de uma conclusão universalmente quantificada. Em Segundos Analíticos I 4, 73b 32-74a 3, por exemplo, Aristóteles argumenta que a demonstração universal não conclui que todo isósceles tem a soma dos ângulos internos igual a dois ângulos retos, mas que todo triângulo tem a soma dos ângulos internos igual a dois ângulos retos, revelando um requisito que envolve o ajuste preciso do extremo menor a partir de condições estabelecidas pelo extremo maior (cf. Seg. An. I 5, 74a 4-6, 13-17, 25-32, 74b 21-26, I 24, 85b 4-15). Para Aristóteles, o predicado "ter a soma dos ângulos internos igual a dois ângulos retos" - daqui para frente, apenas "2R" - se atribui a "isósceles" de um modo que, em algum sentido, é parasitário da atribuição a "triângulo", dado que isósceles tem $2 \mathrm{R}$ na exata medida em que é triângulo. Em outras palavras, a atribuição de "2R" a "isósceles" é entendida como indireta e dependente da atribuição a "triângulo". Nesse contexto, é natural presumir que um silogismo peripatético seja concebido como inferior em relação aos demais - especialmente no que dir. respeito ao grau de cientificidade - já que sua conclusão não poderá satisfazer as exigências de uma legítima conclusão cientifica, tal como ocorre em uma demonstração universal. Já quanto às propriedades dedutivas envolvidas em tal silogismo, não há razão para considerá-lo inferior. Para apreciação detalhada da noção de demonstração universal, ver Angioni (2007).

${ }^{56}$ Ross (1953, p. 464).

Manuscrito - Rev. Int. Fil., Campinas, v. 36, n. 1, p. 5-48, jan.-jun. 2013. 
Ross supõe que o argumento de Shorey pretende estabelecer a exclusão dos termos singulares do domínio de operação da silogística e aponta a passagem 43a 37-40 como evidência textual incompatível com essa exclusão. Temos aqui uma mudança de opinião. De fato, conforme pudemos ver na primeira seção deste artigo, ao tratar do trecho 43a 37-43, na edição comentada do texto grego de Primeiros e Segundos Analíticos, Ross chega a dizer que Aristóteles nunca se vale de termos singulares em seus exemplos de silogismos e argumenta em favor de uma silogística restrita a termos de generalidade intermediária ( đà $\mu \varepsilon т \alpha \xi \grave{u})^{57}$. Agora, ao comentar a passagem 1086a 34-37 de Metafísica XIII (My) 10, Ross reconhece no capítulo 27 de Primeiros Analíticos I uma evidência em favor da inclusão dos termos singulares na silogística. Aparentemente, o próprio Ross não tinha muita convicção a respeito da inclusão ou exclusão dos termos de natureza singular.

De nossa parte, admitimos que a passagem 1086a 34-37 é digna da controvérsia introduzida por Shorey - embora tenhamos mais apreço pela interpretação de Ross. No entanto, mesmo que Shorey tenha razão a respeito do referido trecho de Metafísica XIII $(M y)$ 10, a presença de nomes próprios e designações singulares na silogística não estará ameaçada, porque ainda podemos nos valer de passagens muito mais promissoras para decidir essa questão, passagens nas quais o próprio Aristóteles elabora cômputos silogísticos com termos singulares, como se a presença deles na silogística não lhe figurasse como uma anomalia.

Patzig tinha conhecimento dessas passagens e fez questão de citálas no primeiro capítulo de seu livro, corrigindo o suposto fato, alegado por Ross e Lukasiewicz, de Aristóteles nunca se valer de termos singulares nos exemplos de silogismos que aparecem em Primeiros Analíticos. No entanto, Patzig não recorre a tais passagens a fim de reintroduzir os termos singulares na silogística, mas procura

${ }^{57}$ Idem, 1949, p. 384.

Manuscrito - Rev. Int. Fil., Campinas, v. 36, n. 1, p. 5-48, jan.-jun. 2013. 
desqualificá-las e, assim, reiterar os resultados de seus antecessores. De fato, embora reconheça as ocorrências de "Aristomenes" e "Micalos", no capítulo 33 do Livro I, bem como de "Pitacos", no capítulo 27 do Livro II, Patzig mantém a posição tradicional, que afasta os termos de natureza singular da lógica aristotélica, alegando apenas que a ocorrência de "Pitacos" (70a 16-20) se dá em um silogismo inválido, ao passo que "Aristomenes" e "Micalos" (47b 15ss.) aparecem em premissas das quais nada se segue ${ }^{58}$.

É bem verdade que as ocorrências de "Aristomenes" e "Micalos", no capítulo 33 de Primeiros Analíticos I, estão associadas a pares de premissas dos quais nenhuma conclusão se segue, coisa que o próprio Aristóteles não hesita em admitir. No entanto, embora sejam inconcludentes, esses pares de premissas acomodam seus termos em disposições muito similares àquelas de um silogismo válido (Barbara) ${ }^{59}$, o que lhes confere as feições de que são concludentes, quando na verdade não o são. De acordo com Aristóteles, o que os impede de serem concludentes é o fato de que a premissa maior não é universal ${ }^{60}$. Em 47b 26-28, essa justificativa é apresentada por meio de um pronunciamento que merece alguma atenção. Aristóteles anuncia o fato de a premissa maior não ser universal como quem supõe que, fosse ela universal, o problema estaria resolvido e, assim, o par de premissas seria concludente ${ }^{61}$. Ora, na medida em que Aristóteles atribui o caráter inconcludente dos pares de premissas precisamente às premissas maiores (e não às premissas menores, nas quais ocorrem os termos singulares), presume-se que esses termos não introduzem qualquer característica censurável nos silogismos ali formulados. Assim, o fato de que não estamos diante de pares de premissas concludentes, por si só, não é

\footnotetext{
58 Patzig (1959, §3, p. 4-5).

59 An. Pr. I 33, 47b 21-37.

${ }^{60}$ Idem, 47b 26-29, 34-37 e 38-39.

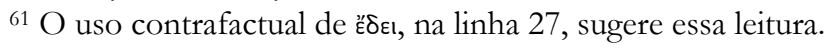

Manuscrito - Rev. Int. Fil., Campinas, v. 36, n. 1, p. 5-48, jan.-jun. 2013. 
suficiente para recusar ao capítulo 33 o papel de evidência em favor de tais termos na silogística ${ }^{62}$.

Quanto à ocorrência de "Pitacos", em Primeiros Analíticos II 27 (70a 16-20), Patzig tem alguma razão em alegar que ela se dá em um silogismo que não é outra coisa senão inválido. No entanto, é preciso ajustar essa alegação, porque Aristóteles não descreve o argumento em questão propriamente como um silogismo, mas como um sinal (опнєі̃o), e, ao que parece, um sinal e um silogismo - um legítimo silogismo e não um mero entimema - estão longe de ser a mesma coisa ${ }^{63}$. Além disso, temos uma ocorrência de "Pitacos", no mesmo capítulo, que é bem mais relevante para a discussão, mas que foi completamente ignorada pelos comentadores.

Em 70a 26-28, Aristóteles formula dois silogismos nos quais aparece o termo singular "Pitacos". Um deles é descrito como refutável

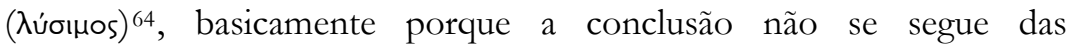
premissas ${ }^{65}$. Não precisamos nos deter nele. Por ora, o silogismo que fora introduzido algumas linhas antes e que foi descrito por Aristóteles

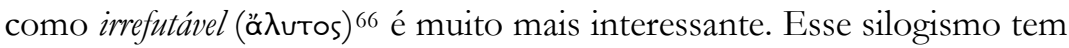
exatamente a formulação paradigmática que Lukasiewicz qualificou pelo adjetivo "peripatético" e à qual negou lugar na lógica aristotélica. Vale a pena citar essa passagem, para marcar bem a presença desse tipo de silogismo na lógica de Aristóteles:

62 M. Malink (2009, p. 119), por exemplo, contrariando Patzig, aponta o capítulo I 33 - bem como II 27, do qual trataremos a seguir - como evidência em favor de termos singulares na silogística. Ver também Mignucci, “Aristotle's Theory of Predication", p. 10, "Parts, Quantification and Aristotelian Predication", p. 11, e Barnes, "Truth, etc.", p. 158-166.

${ }_{63}$ An. Pr. II 27, 70a 24-25.

${ }^{64}$ Ibidem, 30-31 e 34-35.

${ }^{65}$ Ibidem, 27-28 e 30-32.

${ }^{66}$ Ibidem, 29. 


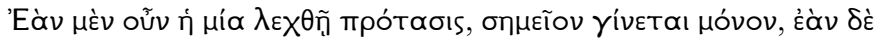

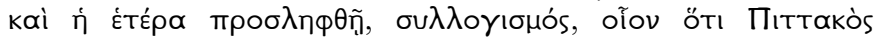

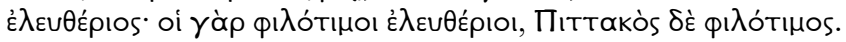

Assim, se somente uma premissa for assumida, há apenas um sinal, ao passo que, se a outra premissa também for assumida, então, há um silogismo, por exemplo: 'Pitacos é destemido, pois os homens de brio são destemidos e Pitacos é homem de brio' (70a 24-27) ${ }^{67}$.

A descrição é inusitada, porque Aristóteles começa pela conclusão. Mas isso não prejudica o resultado a que queremos chegar. O nome próprio "Pitacos" é, sem dúvida, o extremo menor, que aparece como sujeito da premissa menor e da conclusão; “destemido" é o extremo maior, predicado da premissa maior e da conclusão; por fim, a função de mediador fica por conta de "homem de brio". Em uma reconstituição um pouco mais formalizada, temos o seguinte silogismo: todo homem de brio é destemido, Pitacos é (um) homem de brio; logo, Pitacos é destemido.

O leitor mais desconfiado talvez hesite em aceitar que a premissa maior "os homens de brio são destemidos" possa ser formalizada com um quantificador universal, mas há sinais claros de que é assim que devemos concebê-la. Em primeiro lugar, Aristóteles reconhece a legitimidade desse silogismo e supõe que a conclusão decorre das premissas, o que por si só já pressupõe a universalidade da premissa maior. Caso contrário, a conclusão não se impõe. Em segundo lugar, há um pequeno detalhe que causa surpresa nesse capítulo e que merece atenção de nossa parte. Aristóteles justifica o caráter irrefutável do mencionado silogismo, alegando que se trata de um silogismo universal

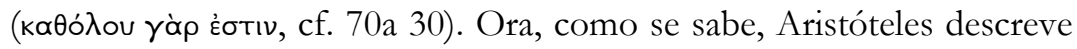
como universais precisamente aqueles silogismos nos quais a conclusão é universal, quais sejam, Barbara, Celarent, Cesare e Camestres. Por isso, ao caracterizar o "silogismo peripatético" como um silogismo universal,

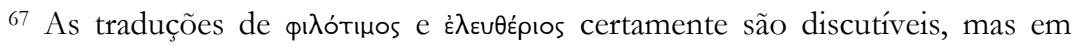
nada afetam os nossos objetivos.

Manuscrito - Rev. Int. Fil., Campinas, v. 36, n. 1, p. 5-48, jan.-jun. 2013. 
Aristóteles pode querer sinalizar que, em algum sentido, a conclusão "Pitacos é destemido" deva ser compreendida como uma proposição fundada em uma atribuição universal ${ }^{68}$, como se o referido "silogismo peripatético", precisamente em razão disso, fosse digno do mesmo status concedido aos demais silogismos universais (Barbara, Celarente, Cesare e Camestres). Essa leitura sugere que a concepção aristotélica de atribuição universal talvez deva ser repensada, já que ela dá sinais de se estender sobre casos para os quais não cabe falar em quantificadores (universais) - é o que parece ocorrer no "silogismo peripatético" acima mencionado.

O aprofundamento desse ponto, no entanto, é algo que ultrapassa o escopo da presente investigação e seu exame deve ser deixado para outra ocasião. A essa altura, o objetivo principal desta seção já nos parece ter sido alcançado, pois consiste apenas em mostrar o que os leitores menos versados nos Analíticos já perceberam há muito tempo, a saber, que o chamado "silogismo peripatético", não só faz parte da lógica aristotélica, mas, mais do que isso, ainda pode desfrutar de um lugar privilegiado no interior da silogística, entre os chamados "silogismos universais". Diante desse quadro, não há dúvida de que os termos de natureza singular têm lugar garantido na lógica de Aristóteles ${ }^{69}$.

${ }_{68}$ Provavelmente, foi inspirado em passagens como essa que J. N. Keynes (1906, p. 102) sugeriu conceber as proposições singulares como uma subclasse de proposições universais. Lukasiewicz tomou nota dessa possibilidade e a considerou totalmente equivocada. Mas, para isso, ignorou completamente o trecho 70a 24-30.

${ }^{69}$ Agradeço ao professor Lucas Angioni (Unicamp) pela prontidão na leitura de versões prévias deste artigo, pelas indicações de passagens para reforçar o argumento e pelas alterações de texto sugeridas, as quais, certamente, contribuíram para melhorar o resultado final aqui apresentado. Agradeço também aos professores Raphael Zillig (UFRGS) e Inara Zanuzzi (UFRGS) pela oportunidade de discutir alguns resultados provisórios deste artigo no Seminário sobre Primeiros Analíticos I 27, organizado pelo professor Raphael e realizado na UFRGS, no ano de 2011. Por fim, também agradeço aos

Manuscrito - Rev. Int. Fil., Campinas, v. 36, n. 1, p. 5-48, jan.-jun. 2013. 


\section{REFERÊNCIAS}

ANGIONI, L. "O Conhecimento Científico no Livro I dos Segundos Analíticos de Aristóteles". Revista de Filosofia Antiga (online), vol. $1, \quad$ n. $1, \quad 2007$ (http://www.filosofiaantiga.com/documents/23.html).

BARNES, J. (ed.). Aristotle: Prior Analytics (trans. by A. J. Jenkinson in Barnes, 1984, vol. 1, p. 39-113).

-Truth, etc., Six Lectures on Ancient Logic. Oxford: Clarendon Press, 2007.

BOCHENSKI, J. Ancient Formal Logic. Amsterdam: North-Holland Publishing, 1951.

CORCORAN, J. "Completeness of an Ancient Logic". Journal of Symbolic Logic, 37, 696-702, 1972.

KEYNES, J. N. Studies and Exercises in Formal Logic (fourth edition rewritten and enlarged). New York: The Macmillan Company, 1906.

LUKASIEWICZ, J. Aristotle's Syllogistic from the Standpoint of Modern Formal Logic. Oxford: Clarendon Press, 1951.

MALINK, M. "A Non-Extensional Notion of Conversion in the Organon". Oxford Studies in Ancient Philosophy, Vol. XXXVII, p. 106-141. Oxford University Press, 2009.

MIGNUCCI, M. Aristotele: Gli analitici primi - Tradurione, introdurione e commento. Naples: Loffredo, 1969.

companheiros de pesquisa, Francine Maria Ribeiro e Mateus Ricardo Fernandes Ferreira (UEM-PR), pela leitura das primeiras versões desse texto e pelas proveitosas sugestões que me fizeram.

Manuscrito - Rev. Int. Fil., Campinas, v. 36, n. 1, p. 5-48, jan.-jun. 2013. 
Aristotle's Theory of Predication, in I. Angelilli and M. Cerezo (eds.), Studies in the History of Logic, 1-20. Berlin, 1996.

Parts, Quantification and Aristotelian Predication, Monist, 83, 3-21, 2000.

PATZIG, G. Aristotle's Theory of the Syllogism: A Logico-Philosophical Study of Book $A$ of the Prior Analytics. Translated by Jonathan Barnes. Dordrecht: Reidel, 1959.

ROSS, W. D. Aristotle's Prior and Posterior Analytics. Oxford: Clarendon Press, 1949.

. Aristotle's Metaphysics. Oxford: Clarendon Press, 1953 (1924).

SHOREY, P. “A Note on Aristotle's Metaphysics 1086b 32-37”. Classical Pbilology, Vol. 8, n. 1, pp. 90-92, 1913.

SMITH, R. Aristotle: Prior Analytics. Indianapolis: Hackett Publishing Company, 1989.

STRIKER, G. Aristotle: Prior Analytics Book I. Oxford: Clarendon Press, 2009. 